\title{
Loss of Cdk5 in breast cancer cells promotes ROS-mediated cell death through dysregulation of the mitochondrial permeability transition pore
}

\author{
Saranya NavaneethaKrishnan ${ }^{1} \cdot$ Jesusa L. Rosales ${ }^{2} \cdot$ Ki-Young Lee $\mathbb{C}^{1}$
}

Received: 9 May 2017 / Revised: 6 November 2017 / Accepted: 7 November 2017 / Published online: 19 January 2018

(c) The Author(s) 2018. This article is published with open access

\begin{abstract}
Cdk5, which plays a role in the development and progression of many human cancers, localizes in the mitochondria, a key determinant of apoptotic cell death. Cdk5 is upregulated in breast cancer cells but it was shown that Cdk5 loss increases chemotherapy-induced apoptosis. However, the molecular mechanism by which Cdk5 loss promotes cell death remains unclear. Here, we investigate the possibility that Cdk5 loss activates the intrinsic apoptotic pathway in breast cancer cells. We demonstrate that Cdk5-deficient breast cancer cells exhibit increased mitochondrial depolarization, mitochondrial ROS levels, and mitochondrial fragmentation that is associated with an increase in both intracellular $\mathrm{Ca}^{2+}$ level and calcineurin activity, and DRP1 S637 dephosphorylation. These events accompany increased apoptosis, indicating that Cdk5 loss promotes mitochondria-mediated apoptosis. To define this apoptotic pathway, we utilized various inhibitors of mitochondrial function. Apoptosis is completely prevented by MPTP inhibition, almost fully inhibited by blocking ROS and unaffected by inhibition of mitochondrial fission, suggesting that apoptosis in breast cancer cells due to Cdk5 loss occurs via a novel mPTP-dependent mechanism that acts primarily through ROS increase.
\end{abstract}

\section{Introduction}

Cyclin-dependent kinase $5(\mathrm{Cdk} 5)$ is a proline-directed serine/threonine kinase that functions in the development and progression of many types of human cancer by regulating cell proliferation, metastasis, DNA repair, checkpoint escape, and apoptosis [1]. Cdk5 expression is particularly upregulated in breast cancer $[2,3]$ and correlated with tumor progression and poor prognosis [2-4]. Interestingly, loss of Cdk5 was found to increase cancer cell sensitivity to chemotherapeutic drugs such as cisplatin and

Electronic supplementary material The online version of this article (https://doi.org/10.1038/s41388-017-0103-1) contains supplementary material, which is available to authorized users.

\section{Ki-Young Lee}

kylee@ucalgary.ca

1 Department of Cell Biology and Anatomy, Arnie Charbonneau Cancer Institute, University of Calgary, Calgary, AB, Canada

2 Department of Biochemistry and Molecular Biology, Snyder Institute for Chronic Diseases, University of Calgary, Calgary, AB, Canada camptothecin, as well as poly ADP ribose polymerase (PARP) inhibitors [5], paclitaxel [6], and bortezomib [7]. However, the precise mechanism that links Cdk5 loss to increased drug sensitivity and cell death, particularly in breast cancer cells, remains to be investigated.

Cdk5 also affects mitochondrial function, which plays a key role in cell death. Previous studies of Cdk5 in the mitochondria have mainly focused on neuronal cells where Cdk5 was identified as an upstream regulator of mitochondrial fission in neurodegenerative conditions [8]. Although Cdk5 was found to protect neurons from apoptotic and necrotic cell death [9], inhibition of Cdk5 activity in prostate, pancreatic, and breast tumors was determined to suppress growth in vitro and in vivo [2, 10-12]. Apoptosis occurs via two major pathways: the extrinsic or death receptor-mediated pathway and the intrinsic or mitochondria-mediated pathway. These pathways are linked [13] and merge at the same final pathway that begins with caspase-3 cleavage and ends with DNA fragmentation, protein degradation, and cross-linking, and apoptotic body formation. In the mitochondrial apoptotic pathway, mitochondria release pro-apoptotic proteins such as cytochrome $\mathrm{C}$, which is required to initiate the apoptosome and to activate caspases. This intrinsic apoptotic pathway requires 
mitochondrial outer membrane permeabilization and mitochondrial permeability transition pore (mPTP) opening in the inner membrane. The mPTP, which contains cyclophilin $\mathrm{D}$ and $\mathrm{F}_{0}-\mathrm{F}_{1}$ ATP synthase [14-17], is a voltage-dependent, high-conductance channel that is activated by mitochondrial $\mathrm{Ca}^{2+}$ overload $[18,19]$ and controls the permeability of the inner mitochondrial membrane. Prolonged mPTP opening leads to decreased membrane potential or mitochondrial depolarization, inhibition of oxidative phosphorylation, generation of reactive oxygen species (ROS), and ATP hydrolysis [20]. It can also cause swelling of the matrix that could lead to outer membrane rupture, facilitating release of intermembrane space (IMS) proteins [21-23], including Smac/DIABLO and Omi/HtrA2, which increase caspase activation by blocking the effects of the inhibitor of apoptosis proteins [24-26].

Cdk5 localizes to the inner mitochondrial membrane [27]. In neurons, Cdk5 regulation of mitochondrial dynamics and the intrinsic apoptotic pathway has been associated with phosphorylation of the GTPase, dynaminrelated protein 1 (DRP1), at Ser 585 (rat)/Ser 616 (human). DRP1 Ser 585 (rat)/Ser 616 (human) phosphorylation inhibits mitochondrial fission in maturing neurons [28] but paradoxically, promotes mitochondrial fission during neuronal injury and in brain tumor-initiating cells [29, 30]. Conversely, DRP1 is phosphorylated at Ser 656 (rat)/Ser 637 (human) by protein kinase A (PKA) and its dephosphorylation by calcineurin induces mitochondrial fission $[31,32]$. Thus, it appears that the consequence of DRP1 phosphorylation on mitochondrial dynamics hinge on the physiological, pathological, and cellular contexts. In cancer cells, the role of Cdk5 in mitochondrial dynamics and mitochondria-mediated cell death remains to be explored.

As Cdk5 loss enhances the sensitivity of breast cancer cells to drug therapy, particularly to PARP inhibitors [5, 33], we used breast cancer cells to understand how Cdk5 loss may regulate mitochondrial events, including the intrinsic apoptotic pathway in these cells. We demonstrate that Cdk5 loss promotes mPTP-induced increase in mitochondrial depolarization, ROS level, and DRP1-Ser 637 dephosphorylation-associated mitochondrial fragmentation, and ultimately cell death.

\section{Results}

\section{Cdk5 loss triggers a robust increase in ROS generation in breast cancer cells}

To identify the cellular events affected by Cdk5 loss in breast cancer cells, we depleted Cdk5 in the MDA MB-231 breast cancer cell model by transfection with Cdk5 siRNAs. Cdk5 was almost completely depleted in these cells $72 \mathrm{~h}$ post-transfection with two different Cdk5 small interfering RNAs (siRNAs; \#1 and \#2; Supplementary Figure 1A). As hyperactivation of Cdk5 causes oxidative stress [34, 35] that promotes death in neuronal cells, we examined the intracellular ROS level in Cdk5-depleted MDA MB-231 cells. Contrary to expectations, by $2^{\prime}, 7^{\prime}$-dichlorofluorescin diacetate (DCFDA) staining and microscopic analysis, we observed increased level of ROS production in MDA MB231 cells depleted of $\mathrm{Cdk} 5$ compared with control cells (Supplementary Figure 1B), indicating that the link between $\mathrm{Cdk} 5$ and oxidative stress in breast cancer cells is distinct from that in neuronal cells [34, 35].

To further examine the effect of Cdk5 loss in breast cancer cells, we extended our investigation to include additional breast cancer cell models, MCF-7 and SKBR-3. As Cdk5 siRNAs \#1 and \#2 have similar efficiency in knocking down Cdk5 and both siRNAs were functionally effective in inducing oxidative stress and mitochondrial dysfunction in MDA MB-231 breast cancer cells (Supplementary Figure 1), we also decided on using only siRNA \#1 in subsequent experiments to avoid unnecessary experimental repetition. Cdk5-depleted breast cancer cells (Fig. 1a (MDA MB-231 and MCF-7) and Supplementary Figure 2A (SKBR-3)) had increased DCFDA staining for intracellular hydrogen peroxide (Fig. 1b and Supplementary Figure 2B). Consistent with microscopic data, flow cytometry analysis indicated a 28\% (MDA MB-231), 40\% (MCF-7), and 30\% (SKBR-3) increase in intracellular hydrogen peroxide in Cdk5-depleted compared with control cells. As mitochondria are a major source of ROS, we also sought to examine ROS levels in this organelle by MitoSOX staining. As shown in Fig. 1c and Supplementary Figure 2C, mitochondrial superoxide anion levels in Cdk5-depleted cells were significantly higher compared with control cells and flow cytometry showed a 45\% (MDA MB-231), 30\% (MCF-7), and 35\% (SKBR-3) increase in mitochondrial superoxide anions in Cdk5-depleted cells compared with control cells.

\section{Loss of Cdk5 reduces mitochondrial membrane potential in breast cancer cells}

As mitochondrial depolarization has been linked to mitochondrial ROS increase [36, 37], we next examined mitochondrial membrane potential in breast cancer cells depleted of Cdk5. Cdk5-depleted MDA MB-231 and MCF7 cells were stained with the fluorescent probe, JC-1. Analysis of ratiometric JC-1 staining by flow cytometry revealed a $27 \%$ and $20 \%$ increase in the number of cells with depolarized mitochondria in Cdk5-depleted MDA MB-231 and MCF-7 cells, respectively, compared with corresponding control cells (Fig. 2a). In addition, analysis of JC-1 staining by flow cytometry revealed a $35 \%$ increase 
A

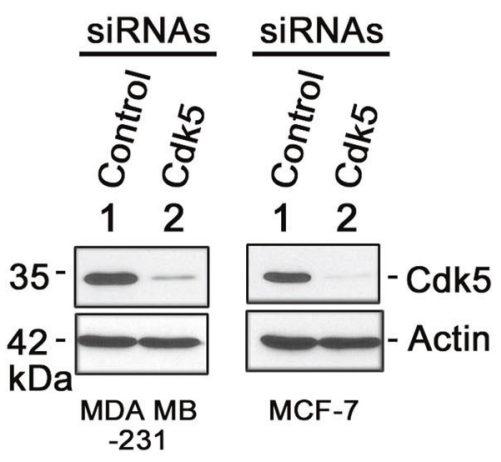

B

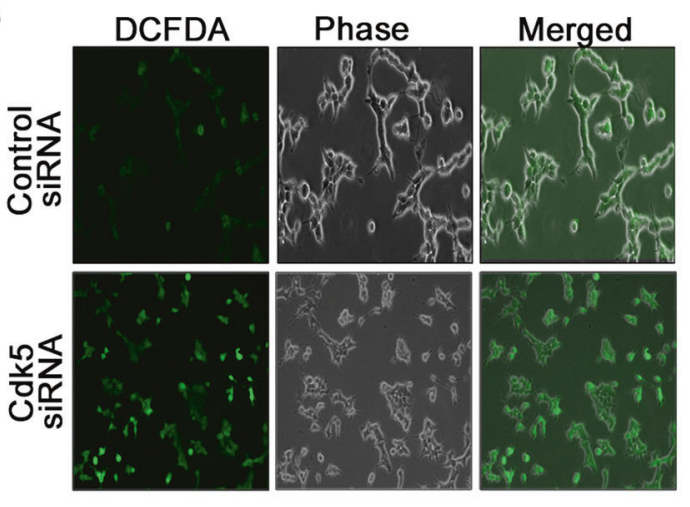

MDA MB-231
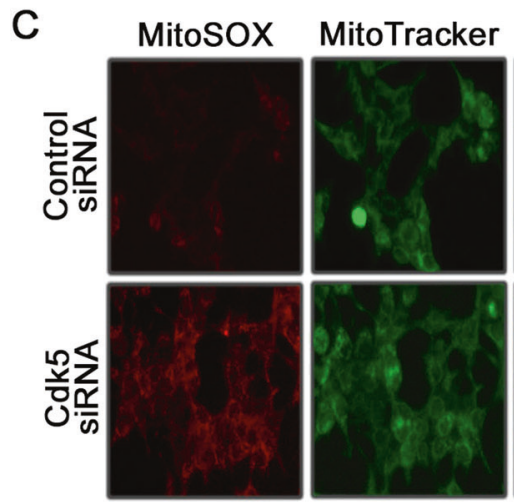

MDA MB-231

Fig. 1 Loss of Cdk5 in breast cancer cells causes a dramatic increase in production of cytoplasmic hydrogen peroxide and mitochondrial superoxide anions. a Cdk5 silencing in MDA MB-231 and MCF-7 breast cancer cells. Following transfection with Cdk5 siRNA (100 nM) for $72 \mathrm{~h}$, cells were lysed and subjected to immunoblotting using a Cdk5 antibody. Blot shown represents one of three blots with similar patterns. Actin blot serves as loading control. b Cytoplasmic hydrogen peroxide and $\mathbf{c}$ mitochondrial superoxide levels were assessed in MDA MB-231 (left panel) and MCF-7 (right panel) cells depleted of Cdk5. After 72-h transfection with Cdk5 siRNA, cells were stained with

in the number of cells with depolarized mitochondria in Cdk5-depleted SKBR-3 cells compared with corresponding control cells (Supplementary Figure 2D). This result suggests reduced mitochondrial membrane potential in cells lacking Cdk5. Consistent with this finding, Cdk5-depleted
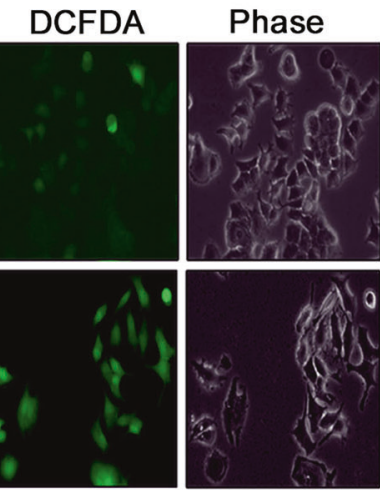

MCF-7
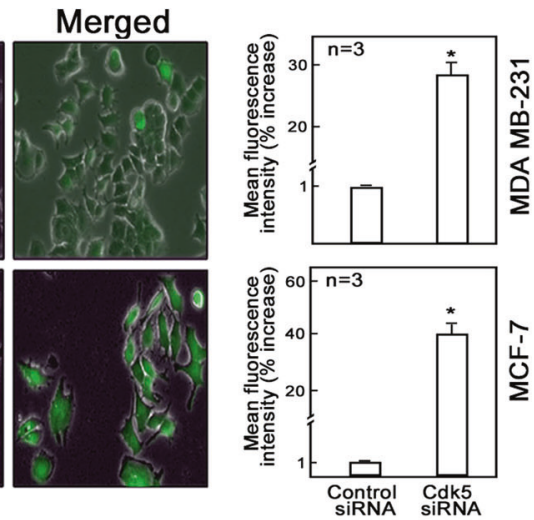

MitosoX

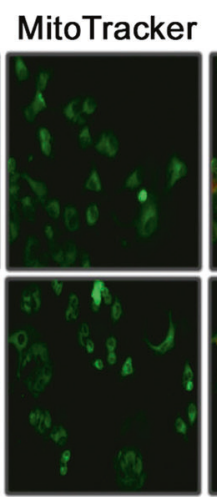

MCF-7
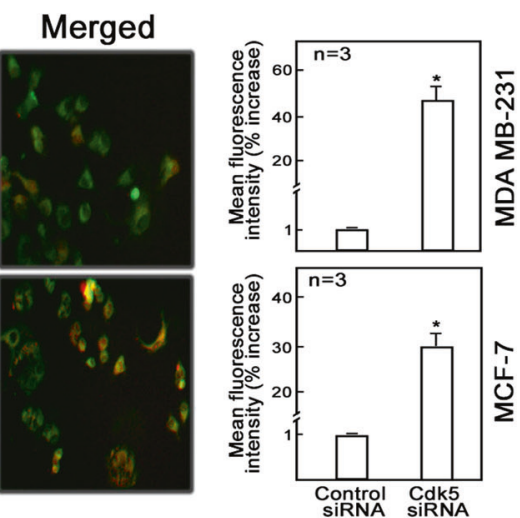

DCFDA $(5 \mu \mathrm{M})$ or MitoSOX red $(5 \mu \mathrm{M})$, and MitoTracker green (200 $\mathrm{nM}$ ) for $30 \mathrm{~min}$ to measure cytoplasmic hydrogen peroxide and mitochondrial superoxide anions, respectively, by fluorescence microscopy and flow cytometry. Cell images were acquired using an Olympus $1 \times 71$ microscope at $\times 160$ magnification. The graphs in (b) and (c) represent \% increase in mean fluorescence intensity over the control siRNA-transfected cells as analyzed by flow cytometry. All values are means \pm SEM from triplicate experiments. Statistical analysis was performed using a Student's $t$-test (unpaired). $*$ indicates statistically significant difference at $p<0.05$

MDA MB-231 and MCF-7 cells have reduced monochromatic tetramethylrhodamine methyl ester perchlorate (TMRM) staining (Fig. 2b), further indicating decreased mitochondrial membrane potential in these cells. Analysis of total cellular ATP levels in Cdk5-depleted MDA MB- 
A

MDA MB-231

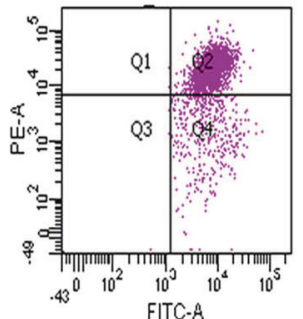

Control siRNA

MCF7

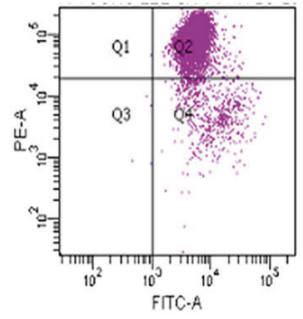

Control siRNA

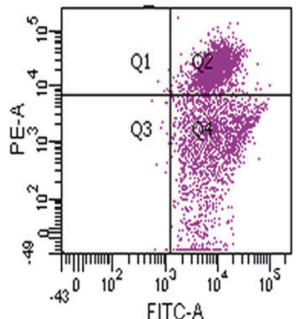

Cdk5 siRNA

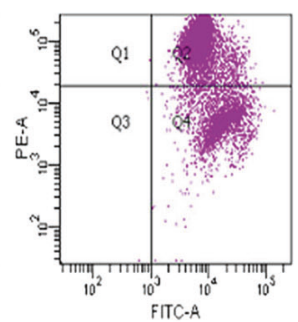

Cdk5 siRNA
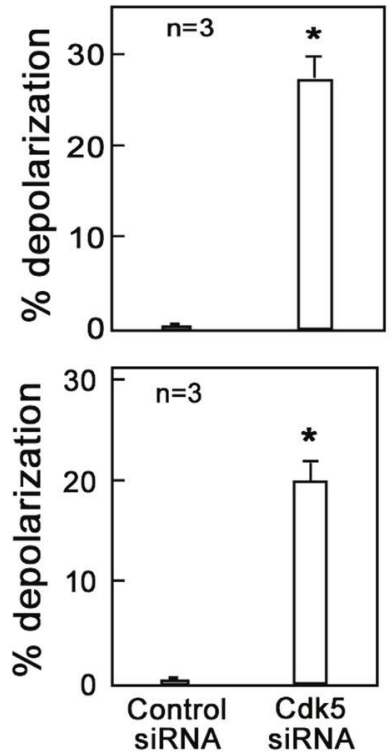

B MDA MB-231

Merged
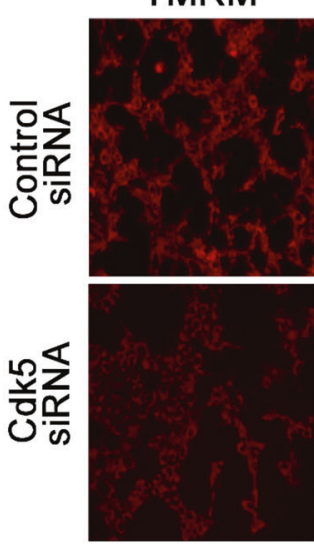

\section{Phase}
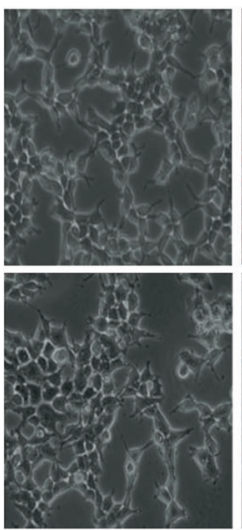

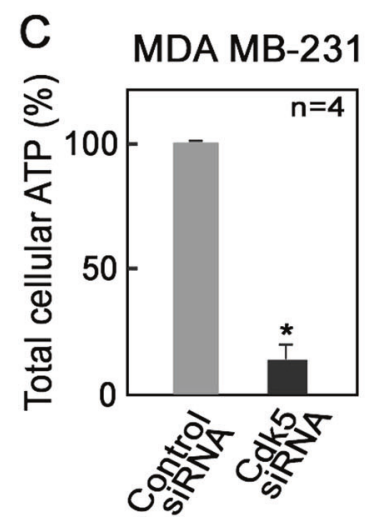

231, MCF-7, and SKBR-3 cells showed an 87\%, 64\%, and $55 \%$ reduction in total ATP concentration, respectively (Fig. 2c and Supplementary Figure 2E). Thus, Cdk5 loss
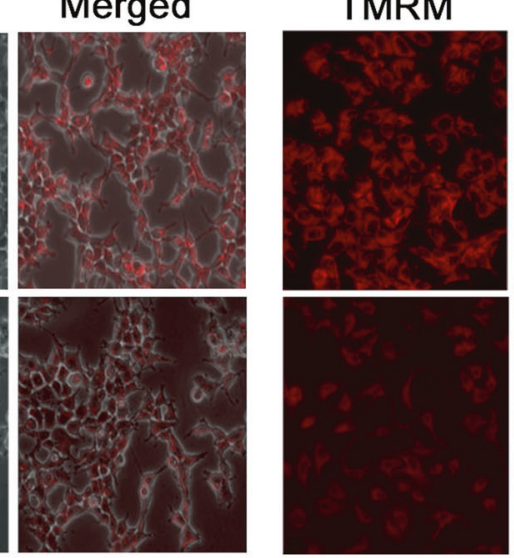

MCF-7

\section{Phase \\ Merged}
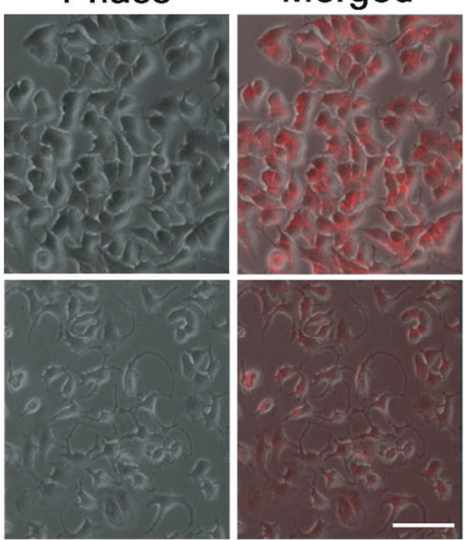

MCF-7

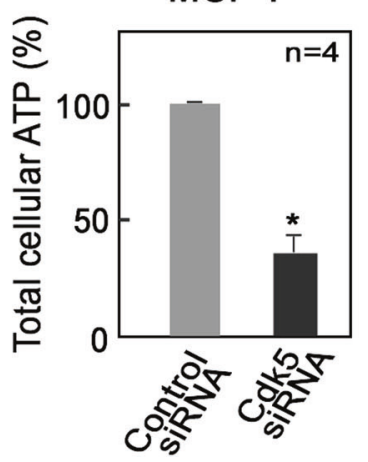

caused an increase in mitochondrial depolarization and subsequent reduction of cellular ATP level. 
Fig. 2 Loss of Cdk5 induces mitochondrial depolarization in breast cancer cells. Analysis of mitochondrial membrane potential using the fluorescent probes, JC-1 and tetramethylrhodamine methyl ester perchlorate (TMRM), in MDA MB-231 and MCF-7 cells depleted of Cdk5. After $72 \mathrm{~h}$ of transfection with Cdk5 siRNA, cells were stained with (a) JC-1 dye $(5 \mu \mathrm{M})$ or (b) TMRM $(5 \mu \mathrm{M})$ for $30 \mathrm{~min}$ at $37^{\circ} \mathrm{C}$ and analyzed by flow cytometry and fluorescence live cell microscopy, respectively. Graphs in (a) represent the percent increase in number of cells with depolarized mitochondria based on the fluorescence intensity of JC-1 in Q4 of the flow cytometry data on the left panel. b Fluorescence microscopy of MDA MB-231 and MCF-7 cells probed with TMRM using an Olympus $1 \times 71$ microscope at $\times 160$ magnification. Scale bar $=100 \mu \mathrm{m}$. Data represent one of three experiments showing similar staining pattern. $\mathbf{c}$ Total cellular ATP level in MDA MB-231 and MCF-7 cells was measured by bioluminescence assay. Briefly, following incubation of cell lysates with reaction buffer containing DTT, luciferin, and luciferase, luminescence was measured at $560 \mathrm{~nm}$ using a plate reader. Values from three (a) or four (c) independent experiments are expressed as means \pm SEM. * indicates $p<$ 0.05 using the Student's $t$-test (unpaired)

\section{Cdk5 loss induces mitochondrial fragmentation that is accompanied by DRP1-S637 dephosphorylation resulting from increased intracellular $\mathrm{Ca}^{2+}$ level and calcineurin activity}

Previous studies indicate that mitochondrial depolarization in HeLa cells causes dephosphorylation of Drp1 at S637 by calcineurin and such dephosphorylation promotes mitochondrial fission [32]. As activity of calcineurin is dependent upon $\mathrm{Ca}^{2+}$ binding, we examined whether increased mitochondrial depolarization in breast cancer cells lacking Cdk5 affects intracellular $\mathrm{Ca}^{2+}$ level and calcineurin activity in these cells. As shown in Fig. 3a, intracellular $\mathrm{Ca}^{2+}$ levels in Cdk5-depleted MDA MB-231 and MCF-7 cells were higher compared with control cells. Similarly, calcineurin activity was elevated in Cdk5-depleted cells (Fig. 3b). We then examined the phosphorylation status of DRP1-S637 in these cells. Consistent with an increase in both intracellular $\mathrm{Ca}^{2+}$ levels and calcineurin activity, we observed that Drp1 S637 phosphorylation was lower in Cdk5-depleted MDA MB-231 and MCF-7 cells compared with control cells (Fig. 3c).

Mitochondrial fusion and fission play important roles in the maintenance, integrity, and bioenergetics capacity of the mitochondrial network. Imbalance of mitochondrial fission and fusion induces various cellular pathological pathways, including apoptosis, mitophagy, and autophagy [38, 39]. Because HeLa mitoDsRed2 cells, which express stable mitochondrial-targeted DsRed2 fluorescence (mitoRFP), are frequently used to study mitochondrial dynamics such as fusion and fission events [40, 41], we used these cells to examine mitochondrial dynamics following $\mathrm{Cdk} 5$ depletion. As with Cdk5-depleted MDA MB-231 and MCF-7 breast cancer cells, HeLa mitoDsRed2 cells depleted of Cdk5 (Supplementary Figure 3A) exhibited increased production of intracellular hydrogen peroxide and mitochondrial superoxide anions (Supplementary Figure 3B, upper and lower panels, respectively). A higher percentage of these cells also had depolarized mitochondria compared with control cells (Supplementary Figure 3C). We then looked at mitochondrial fragmentation in these cells by confocal microscopy. As shown in Fig. 3d, Cdk5 knockdown HeLa mitoDsRed 2 cells exhibited considerable increase in mitochondrial fragmentation, whereas control cells had more fused mitochondria. Quantitative analysis (Fig. 3e) showed fragmented mitochondria in 34\% of the Cdk5-depleted cells and in only $5 \%$ of the control cells. Conversely, fused and elongated mitochondria were observed in $18 \%$ of the Cdk5depleted cells and in $58 \%$ of the control cells. Next, we examined mitochondrial fragmentation in MDA MB-231 breast cancer cells by confocal microscopy (Fig. 3f). As with Cdk5-depleted HeLa mitoDsRed 2 cells, Cdk5 knockdown MDA MB-231 cells showed considerable increase in mitochondrial fragmentation, whereas control cells had more fused mitochondria. Quantitative analysis (Fig. 3g) showed fragmented mitochondria in $64 \%$ of the Cdk5depleted cells and in only $19 \%$ of the control cells. Conversely, fused and elongated mitochondria were observed in $10 \%$ of the Cdk5-depleted cells and in $50 \%$ of the control cells.

To eliminate the possibility that the observed increase in mitochondrial fragmentation following Cdk5 depletion in MDA MB-231 breast cancer cells (Figs. 3f, g) was due to increased rate of mitochondrial biogenesis, we examined the mtDNA copy number in these cells by semiquantitative reverse transcriptase-PCR and quantitative real time PCR and determined the mitochondrial mass by MitoTracker green staining and flow cytometry. Our results showed that Cdk5 depletion did not alter the mtDNA copy number (Supplementary Figure 4A and B) and mitochondrial mass (Supplementary Figure 4C) in MDA MB-231 and MCF-7 cells, indicating that our observed increase in mitochondrial fragmentation in Cdk5-depleted cells was not due to increased mitochondrial biogenesis.

\section{Loss of Cdk5 promotes apoptosis via the mitochondria-mediated pathway}

As defects in the mitochondria could induce apoptosis, we examined whether Cdk5 loss in breast cancer cells promotes apoptosis. As shown in Fig. 4a, Cdk5-depleted MDA MB231 and MCF-7 cells subjected to Annexin V/7-aminoactinomycin D (7-AAD) staining and flow cytometry showed increased apoptosis compared with control cells: $39 \%$ vs $2 \%$ in MDA MB-231 cells and $23 \%$ vs $1 \%$ in MCF7 cells. To determine whether increased apoptosis in Cdk5depleted cells was due to activation of the intrinsic apoptotic pathway, we analyzed the levels of pro-caspase-3 and -9 and their active forms in Cdk5-depleted MDA MB-231 and 
A
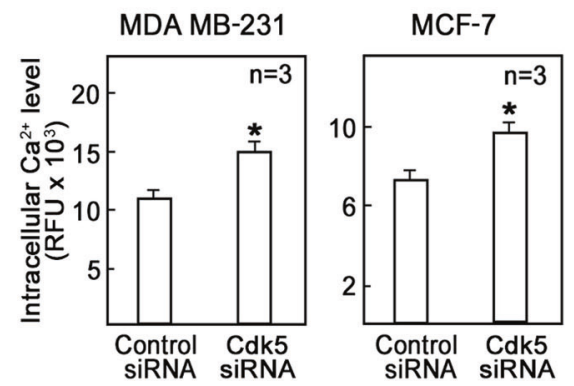

C

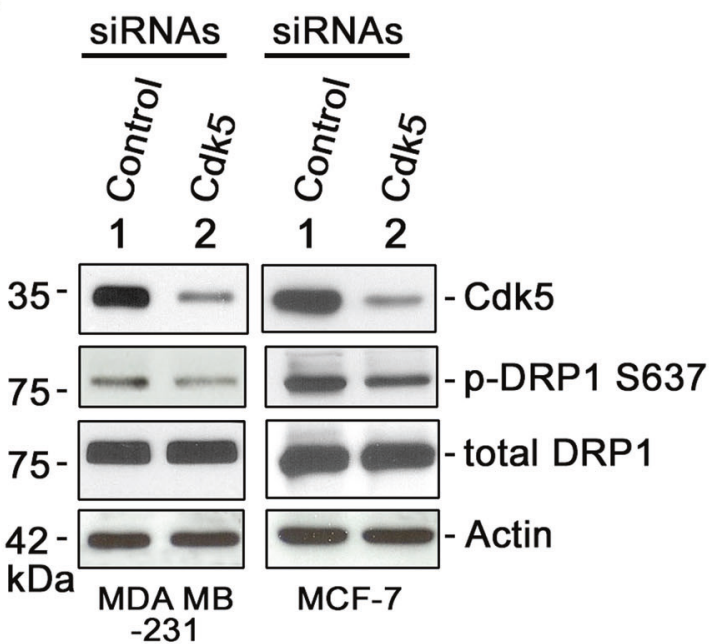

B
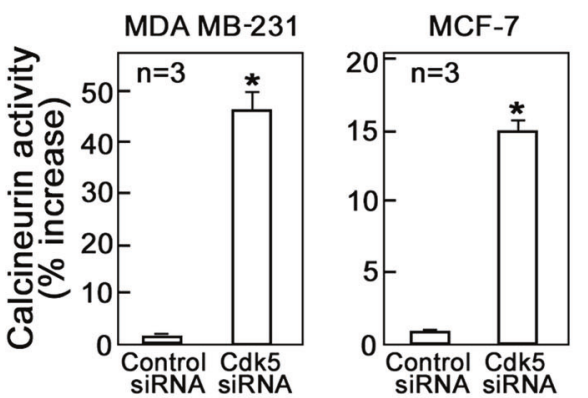

D
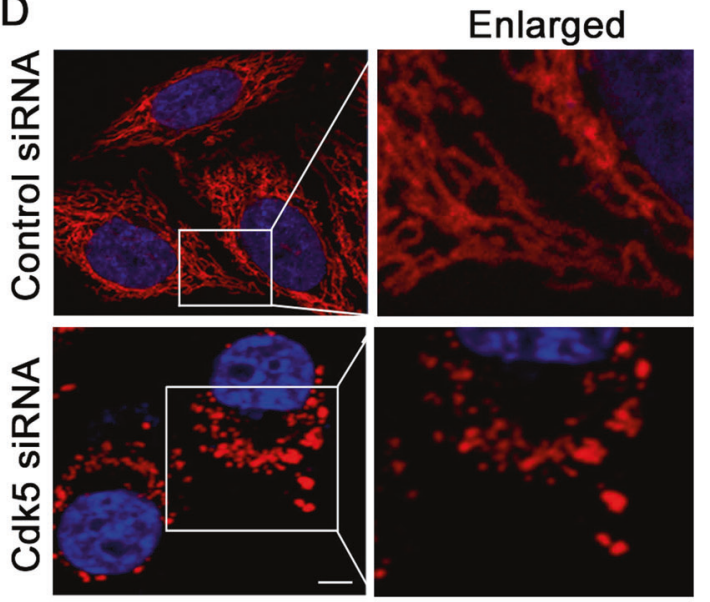

$E$

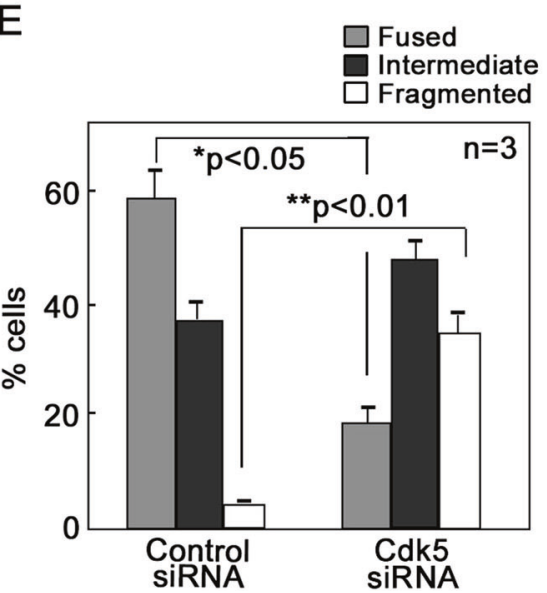

$\mathrm{F}$

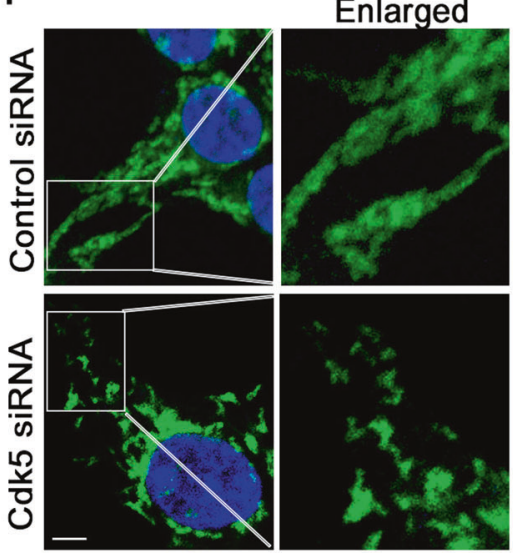

G

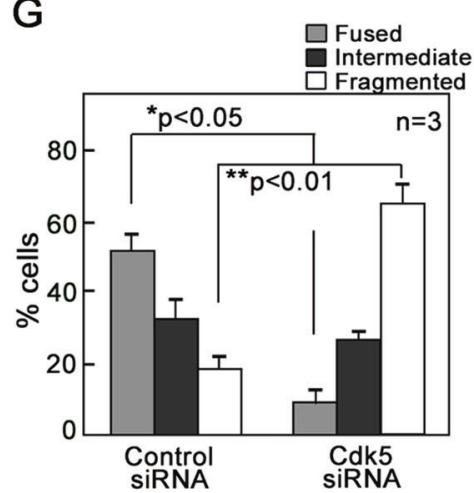

Fig. 3 Cdk5 loss induces mitochondrial fragmentation that is accompanied by DRP1-S637 dephosphorylation that results from an increase in both intracellular $\mathrm{Ca}^{2+}$ level and calcineurin activity. MDA MB-231 and MCF-7 cells transfected with Cdk5 or control siRNA for $72 \mathrm{~h}$ were examined for (a) intracellular $\mathrm{Ca}^{2+}$ level and (b) calcineurin activity as described in Materials and methods section. Intracellular $\mathrm{Ca}^{2+}$ level was measured by Fluo-4 AM $(5 \mu \mathrm{M})$ staining for $30 \mathrm{~min}$ at $37^{\circ} \mathrm{C}$. Calcineurin activity was assessed by colorimetric assay (Abcam) and data were normalized based on control siRNA-treated cells and thus, the graph represents \% increase in calcineurin activity over the control siRNA-transfected cells. Values are from three independent experiments and expressed as means \pm SEM. * indicates $p<$ 0.05 using Student's $t$-test (unpaired). c Level of DRP1 phosphorylation at S637 in MDA MB-231 and MCF-7 cells depleted of Cdk5 and in corresponding control cells. Cell lysates were subjected to immunoblot analysis using phospho S637-specific and total DRP1 antibodies as well as Cdk5 and actin antibodies. Blot shown represents one of three blots with similar patterns. Actin blot serves as a loading control. HeLa mitoDSRed 2 cells (d) and MDA MB-231 (f) transfected with Cdk5 or control siRNA were subjected to confocal microscopy (ZEN lite) at 40x oil immersion. Images on the right panel are magnified views of the boxed areas on the left panel. Scale bar $=5 \mu \mathrm{m}$. Quantitative analysis represent percentage of fused, intermediate, and fragmented mitochondria in HeLa mitoDS cells (e) and MDA MB-231 (g) transfected with Cdk5 or control siRNA. Analysis was performed blindly in 150 cells per treatment group. Values are means \pm SEM from three independent experiments. $*$ and $* *$ indicates $p<0.05$ and $p$ $<0.01$, respectively, using the Student's $t$-test (unpaired) 
A

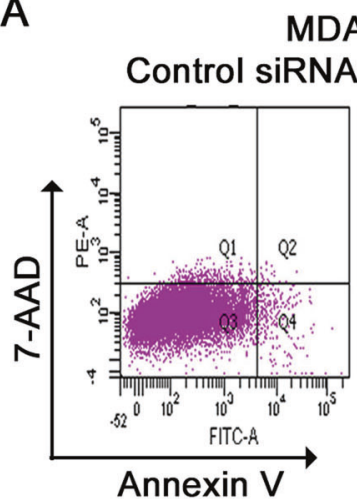

MDA MB-231
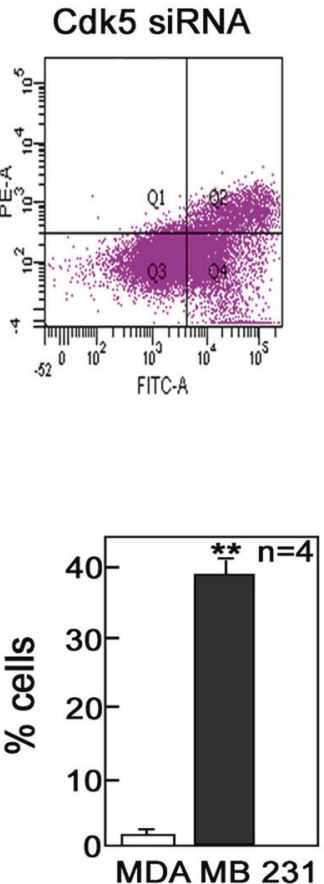

B

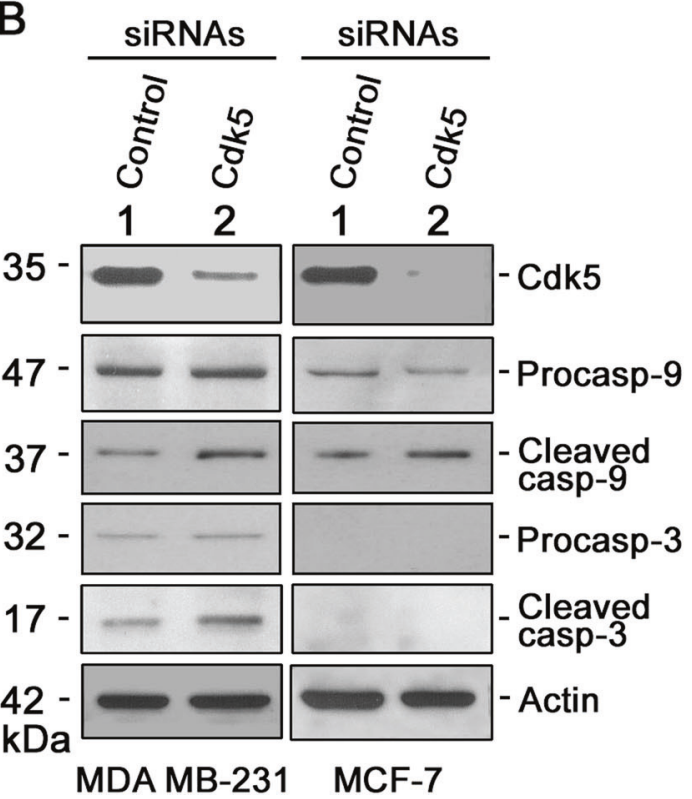

Fig. 4 Depletion of Cdk5 induces mitochondria-mediated apoptosis in breast cancer cells. a Annexin V/7-AAD staining and flow cytometry to detect apoptosis in MDA MB-231 and MCF-7 cells depleted of Cdk5 and corresponding controls. Values are means \pm SEM from four independent experiments. $* *$ indicate statistically significant difference at $p<0.05$, using the Student's $t$-test (unpaired). Q1, Q2, Q3, and Q4 represent necrotic, late apoptotic, viable, and early apoptotic cells,

MCF-7 cells. As shown in Fig. 4b, Cdk5 depletion caused an increase in cleaved caspase-9 level in both MDA MB231 and MCF-7 cells but an increase in cleaved caspase-3 level only in MDA MB-231 cells, which was expected as
MCF-7

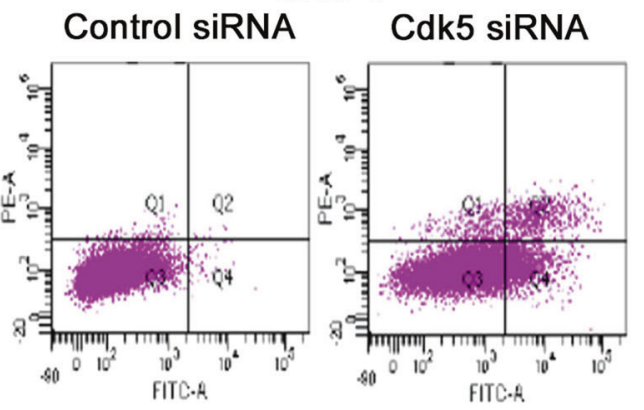

\section{Control siRNA}

Cdk5 siRNA
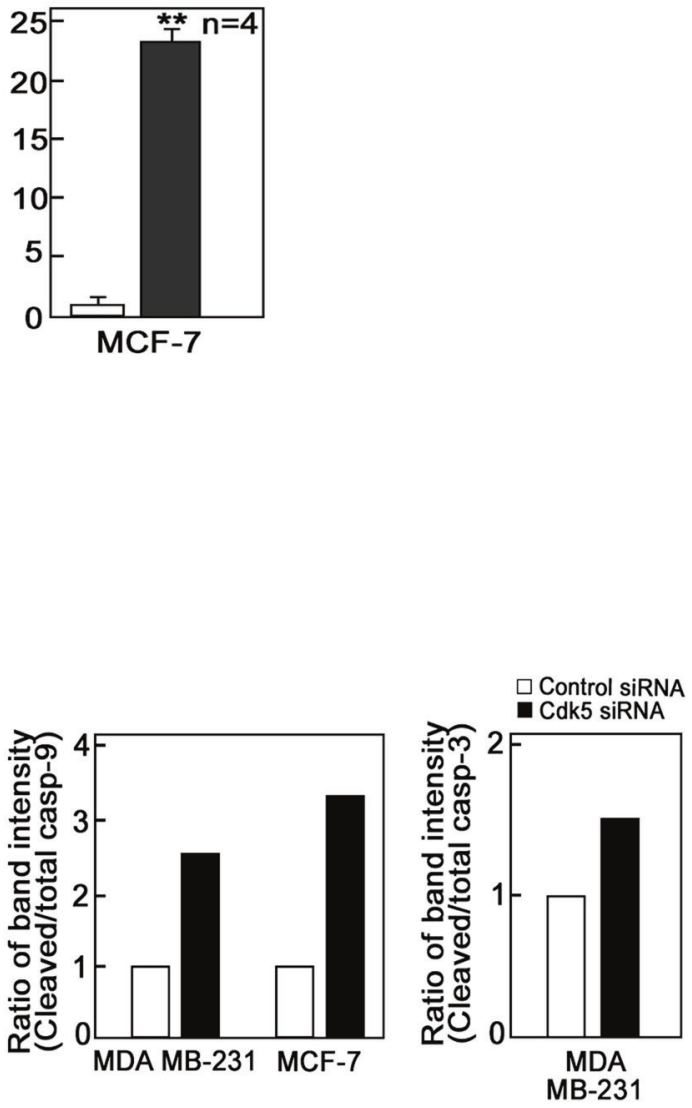

respectively. b Immunoblot analysis of pro-caspase- 9 and -3 and their cleaved forms in MDA MB-231 and MCF-7 cells transfected with Cdk5 or control siRNA.. Blot shown represents one of three blots with similar patterns. Actin blot serves as a loading control. The right panel shows ratios of cleaved/total caspase-9 (in MDA MB-231 and MCF-7 cells) and caspase-3 (in MCF-7 cells)

caspase-3 is not expressed in MCF-7 cells [42]. These findings indicate that $\mathrm{Cdk} 5$ loss induces cell death through the intrinsic apoptotic pathway that involves caspase- 3 and/ or caspase-9 activation. 
A
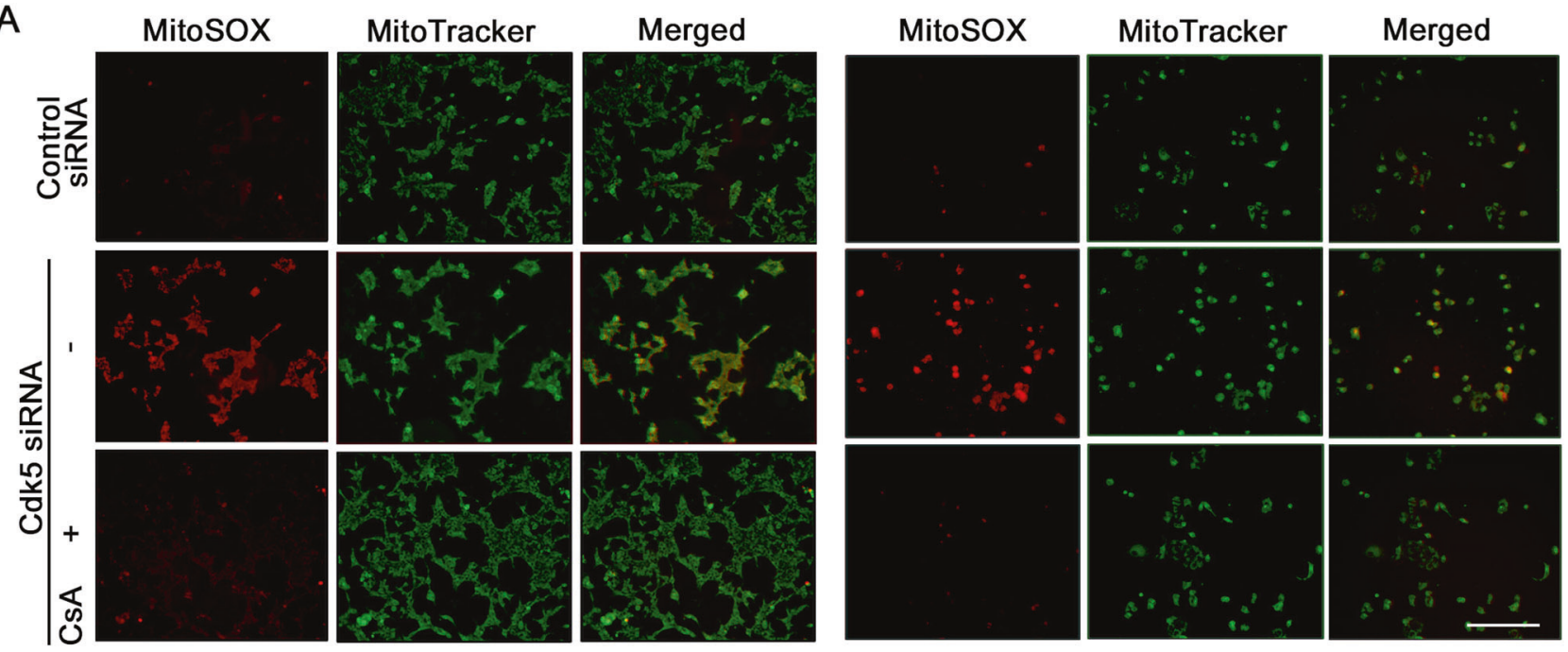

MDA MB-231
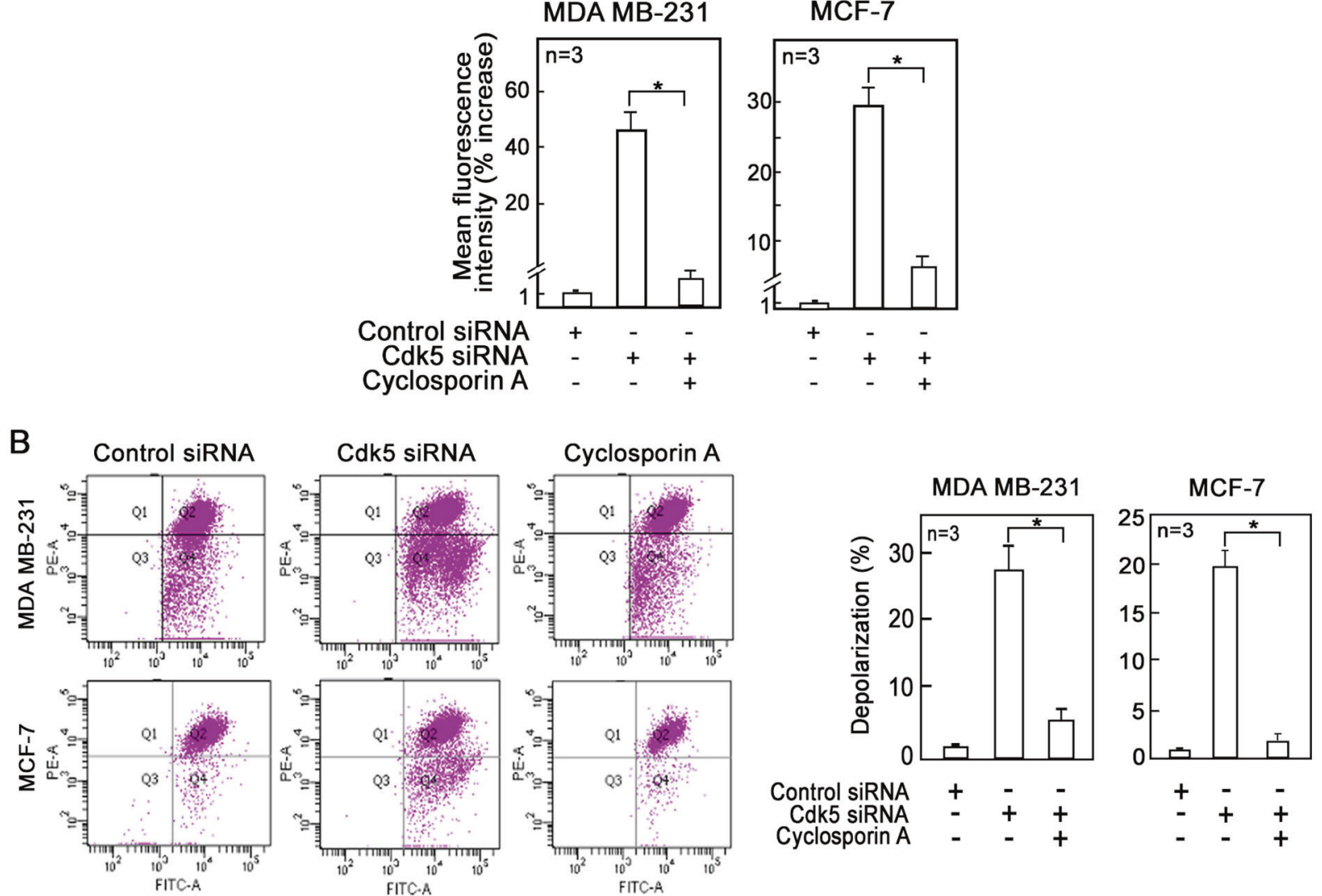

Fig. 5 Inhibition of mPTP prevents mitochondrial ROS increase and depolarization in breast cancer cells depleted of Cdk5. a Fluorescence microscopy of Cdk5-depleted MDA MB-231 (left panel) and MCF-7 (right panel) cells treated or untreated with CsA $(1 \mu \mathrm{M}$ for $24 \mathrm{~h})$ and stained with MitoSOX red $(5 \mu \mathrm{M})$ and MitoTracker green $(200 \mathrm{nM})$ to assess mitochondrial superoxide anion levels. Images were acquired using Olympus $1 \times 71$ at $\times 100$ magnification. Scale bar $=100 \mu \mathrm{m}$. Graphs represent the \% increase in mean fluorescence intensity of cells

stained with MitoSOX red as measured by flow cytometry. Values are means \pm SEM from three independent experiments. Asterisk indicates $p<0.05$ using a Student's $t$-test (unpaired). b Flow cytometry analysis of Cdk5-depleted MDA MB-231 and MCF-7 cells treated or untreated with CsA $(1 \mu \mathrm{M})$ and stained with JC-1 dye to measure mitochondrial membrane potential. Values represent means \pm SEM from three independent experiments. * indicates statistically significant difference at $p<0.05$ using one-way ANOVA

As ROS increase and mitochondrial depolarization and fragmentation, which we observed in Cdk5-depleted breast cancer cells, have been shown to influence each other [43,
44], we sought to identify the sequence of mitochondrial events following Cdk5 depletion in breast cancer cells. 

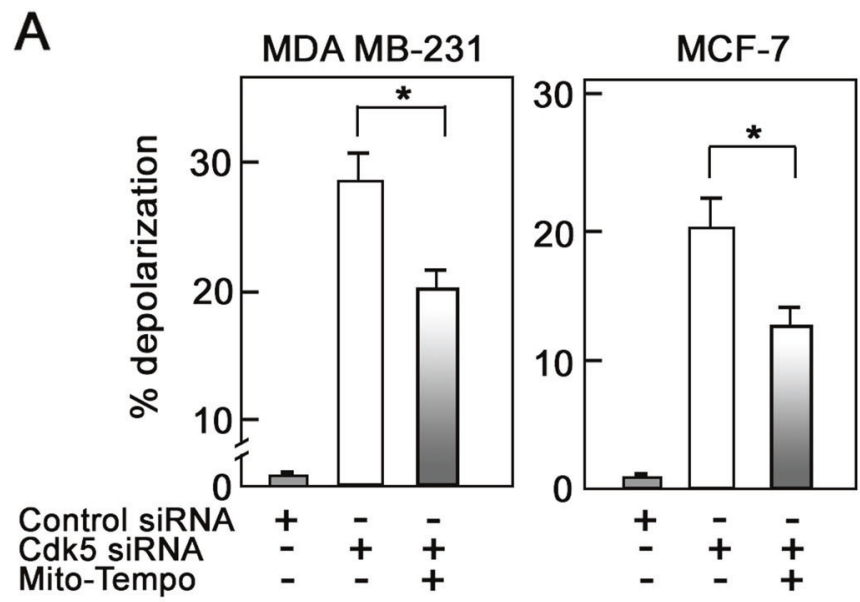

B
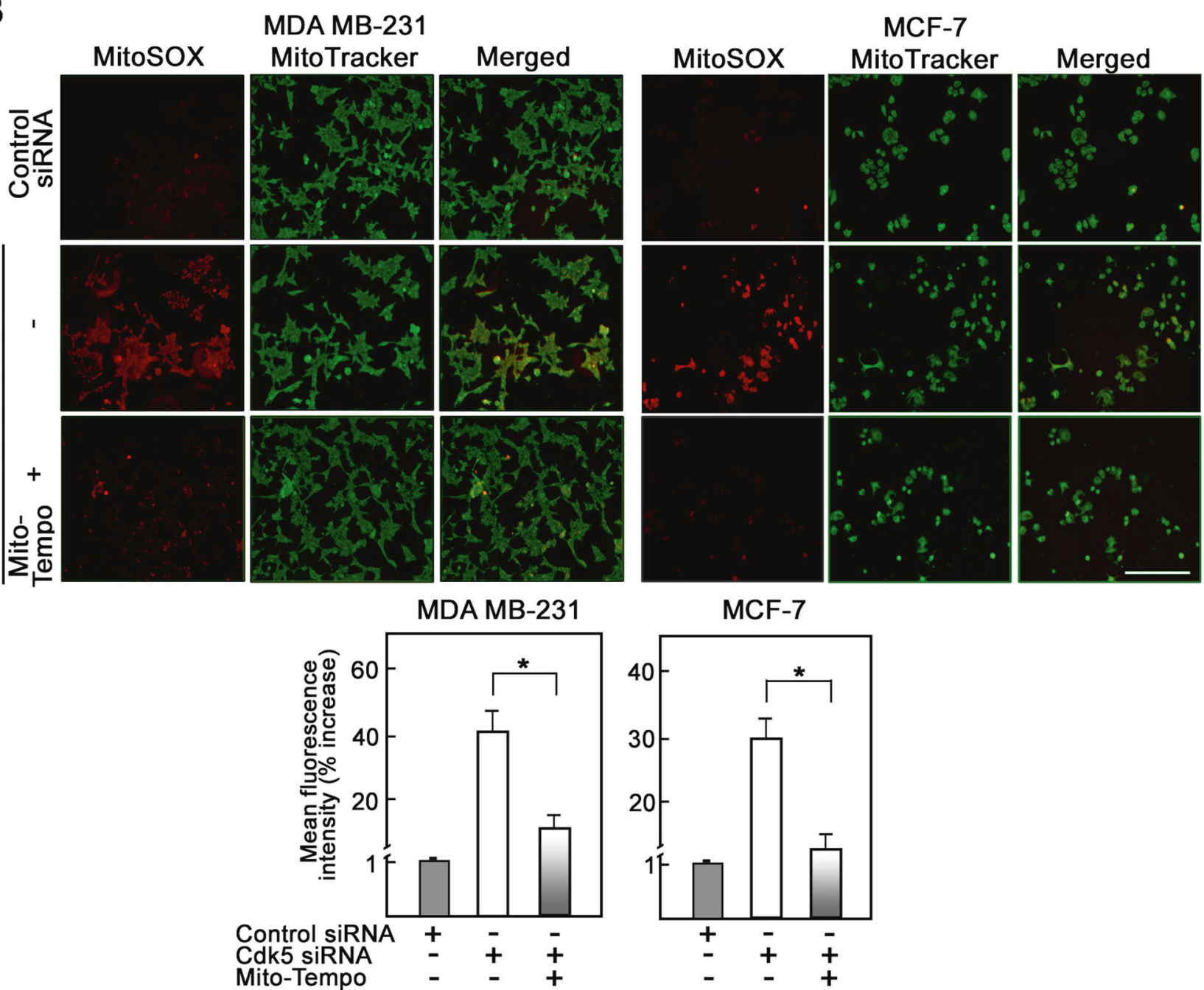

Fig. 6 Specific scavenging of mitochondrial ROS partially reverses mitochondrial depolarization induced by loss of Cdk5 in breast cancer cells. a Flow cytometry analysis of Cdk5-depleted MDA MB-231 and MCF-7 cells treated or untreated with Mito-Tempo $(5 \mu \mathrm{M})$ then stained with JC-1 dye to measure mitochondrial membrane potential. Values represent means \pm SEM from three independent experiments. * indicates statistically significant difference at $p<0.05$ using one-way ANOVA. b Fluorescence microscopy of Cdk5-depleted MDA MB231 (left panel) and MCF-7 (right panel) cells treated or untreated with

Mito-Tempo $(5 \mu \mathrm{M})$ for $24 \mathrm{~h}$ then stained with MitoSOX red $(5 \mu \mathrm{M})$ and MitoTracker green $(200 \mathrm{nM})$ to assess mitochondrial superoxide anion level. Images were acquired using Olympus $1 \times 71$ at $\times 100$ magnification. Scale bar $=100 \mu \mathrm{m}$. Graphs represent the $\%$ increase in mean fluorescence intensity of cells stained with MitoSOX red as measured by flow cytometry. Values are means \pm SEM from three independent experiments. Asterisk indicates $p<0.05$ using a Student's $t$-test (unpaired) 
A

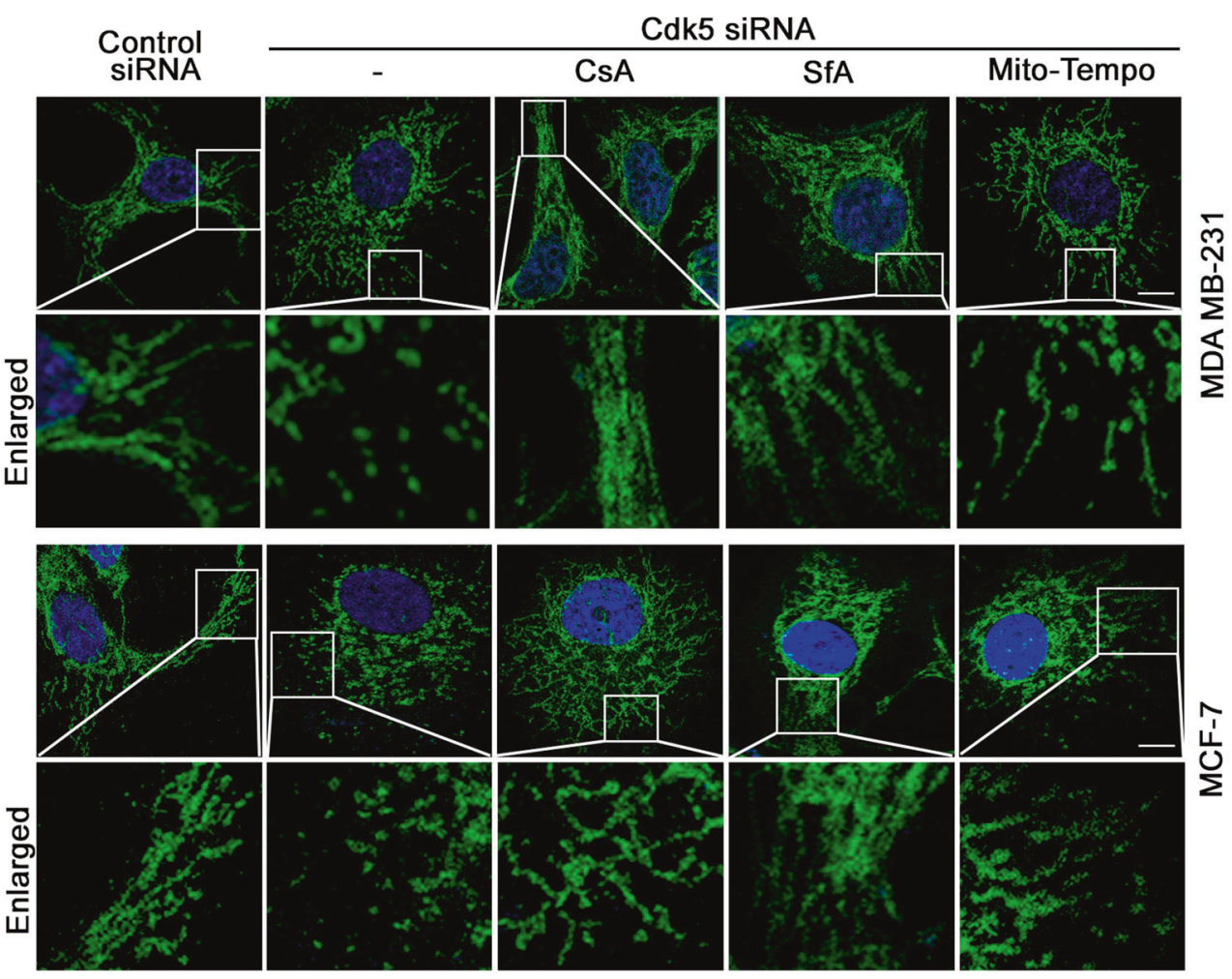

B
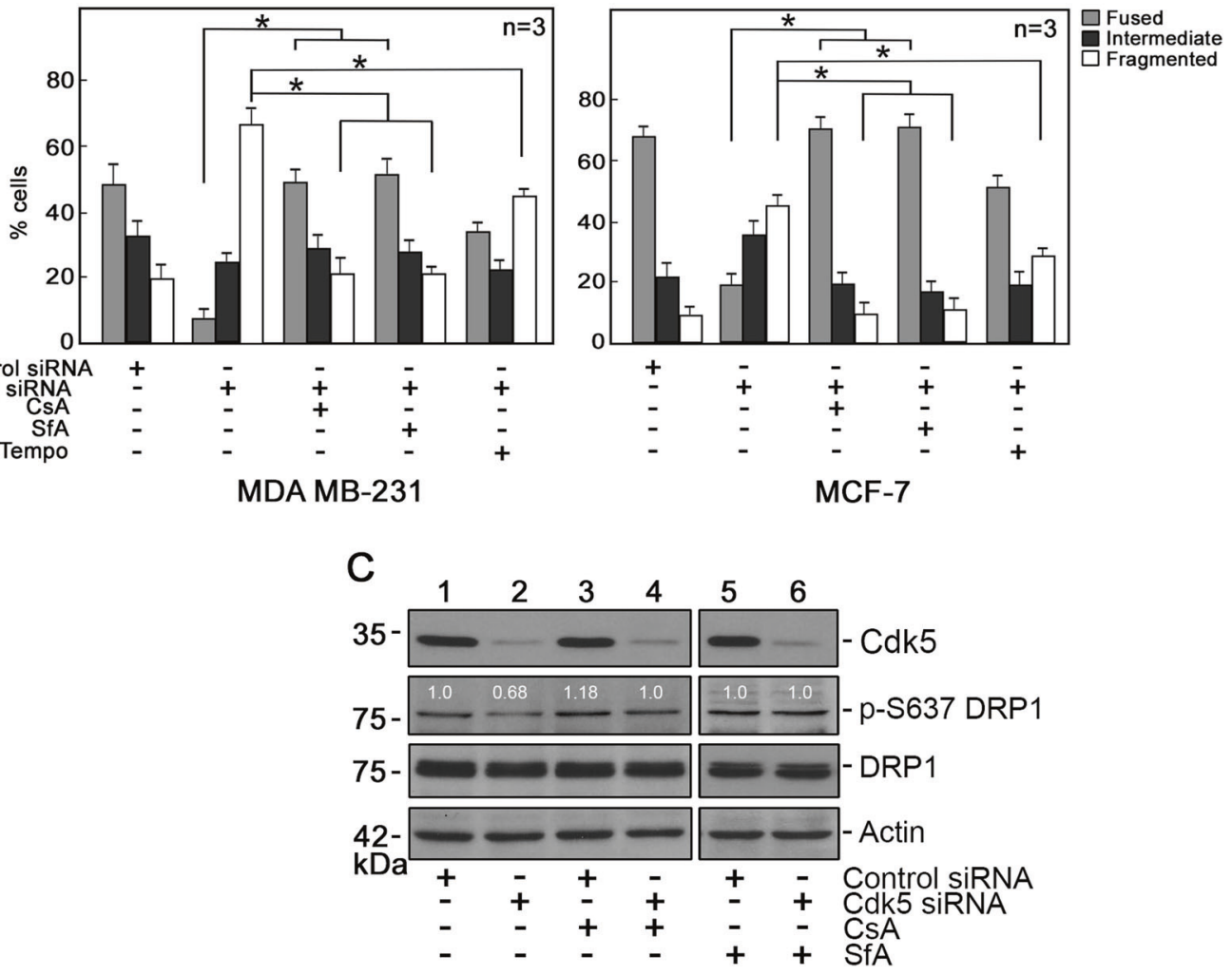
Fig. 7 Mitochondrial fragmentation resulting from loss of Cdk5 is a downstream event of mPTP opening and subsequent mitochondrial depolarization. a Confocal microscopy of mitochondria in Cdk5depleted MDA MB-231 (upper two panels) and MCF-7 (lower two panels) cells treated or untreated with CsA $(1 \mu \mathrm{M})$ or SfA $(2 \mu \mathrm{M})$ and Mito-Tempo $(5 \mu \mathrm{M})$. Images were acquired using a ZEN lite microscope under 40x oil immersion. Scale bar $=5 \mu \mathrm{m}$. b Quantification of fused, intermediate and fragmented mitochondria in MDA MB-231 and MCF-7 cells subjected to the indicated treatments. Analysis was performed blindly in 150 cells per treatment group. Values are means \pm SEM from three independent experiments. $*$ indicates statistically significant difference at $p<0.05$ by one-way and two-way ANOVA. c Immunoblot analysis of DRP1 phosphorylation in Cdk5-depleted MDA MB-231 cells. Cell lysates $(50 \mu \mathrm{g})$ were probed with phosphospecific DRP1 S637 antibody and total DRP1 antibody. Blot shown represents one of three blots with similar patterns. Actin blot serves as a loading control

\section{Inhibition of mPTP prevents mitochondrial depolarization and ROS increase in Cdk5-depleted breast cancer cells}

Because prolonged opening of $\mathrm{mPTP}$ could result in mitochondrial depolarization and decreased synthesis of mitochondrial ATP, consequently leading to cell death [45], we sought to examine whether mPTP opening caused the observed mitochondrial dysfunction following Cdk5 loss in breast cancer cells. To do so, we examined the effect of the mPTP inhibitor, cyclosporin A (CsA), on the ROS increase and mitochondrial depolarization in cells depleted of Cdk5. MDA MB-231, MCF-7, and SKBR-3 cells depleted of Cdk5 and treated with CsA were stained with MitoSOX red and JC-1 to assess mitochondrial ROS level and membrane potential, respectively. Both fluorescence microscopy (Fig. 5a, upper panel) and flow cytometry (Fig. 5a, lower panel and Supplementary Figure 5A) showed that CsA almost completely inhibited the production of mitochondrial superoxide anions in cells depleted of Cdk5. As expected, CsA almost fully inhibited mitochondrial depolarization in Cdk5-depleted cells (Fig. 5b and Supplementary Figure 5B). Treatment of the Cdk5-depleted cells with another mPTP inhibitor, sanglifehrin A (SfA) similarly reduced mitochondrial ROS production (Supplementary Figure 6A) and membrane potential (Supplementary Figure 6B) in these cells, indicating that mPTP opening lies upstream of mitochondrial depolarization and ROS increase that results from Cdk5 loss.

\section{Specific inhibition of mitochondrial ROS partially reverses mitochondrial depolarization due to Cdk5 loss in breast cancer cells}

We then examined the effect of Mito-Tempo, a mitochondrial ROS scavenger, on mitochondrial depolarization in MDA MB-231, MCF-7, and SKBR-3 cells depleted of
Cdk5. As shown in Fig. 6a and Supplementary Figure 5B, Mito-Tempo only partially reduced mitochondrial depolarization in Cdk5-depleted cells. As expected, fluorescence live cell microscopy (Fig. 6b, upper panels), as well as flow cytometry (Fig. 6b, lower panels and Supplementary Figure 5A) showed that Mito-tempo almost completely quenched the mitochondrial superoxide anions in Cdk5-depleted cells. These observations further suggest that mitochondrial depolarization lies upstream of ROS increase but that mitochondrial depolarization in Cdk5-depleted cells is partially due to ROS increase in these cells.

\section{Mitochondrial fragmentation due to Cdk5 loss is a downstream event of mPTP opening and mitochondrial depolarization}

To examine whether mitochondrial fragmentation resulting from Cdk5 loss occurs via mPTP opening, Cdk5-depleted breast cancer cells and HeLa mitoDsRed 2 cells were treated with the mPTP inhibitors, CsA and SfA. As shown in Figs. $7 \mathrm{a}, \mathrm{b}$ and Supplementary Figure 7, mitochondrial fragmentation in these cells was almost completely inhibited following CsA or SfA treatment, further supporting our view that $\mathrm{mPTP}$ opening lies upstream of mitochondrial fragmentation. We then examined the effect of the ROS scavenger, Mito-Tempo, on mitochondrial fragmentation in Cdk5-depleted breast cancer, and HeLa mitoDsRed2 cells. As shown in Figs. 7a, b and Supplementary Figure 7, treatment with Mito-tempo also partially inhibited mitochondrial fragmentation in these cells, suggest that ROS increase also partially contribute to mitochondrial fragmentation. As CsA and SfA prevented mitochondrial fragmentation in Cdk5-depleted cells, we checked whether these inhibitors also affect DRP1 phosphorylation in these cells. As shown in Fig. 7c, DRP1 S637 is dephosphorylated in cells depleted of Cdk5 but CsA and SfA reversed such dephosphorylation, suggesting that $\mathrm{mPTP}$ inhibition by CsA and SfA prevented mitochondrial fragmentation in Cdk5-depleted cells by inhibiting mitochondrial depolarization and subsequently preventing calcineurin dephosphorylation of Drp1 S637.

\section{mPTP inhibition prevents breast cancer cell death induced by loss of Cdk5}

Finally, we sought to examine the effects of CsA, SFA, Mito-Tempo, and Mdivi-1 on the survival of Cdk5-depleted breast cancer cells. As shown in Fig. 8, Cdk5 loss caused death in $40 \%$ and $30 \%$ of MDA MB-231 and MCF-7 cells, respectively, on day 3 following Cdk5 depletion. The mPTP inhibitors, CsA and SFA, completely prevented this effect, showing $100 \%$ survival in cells lacking Cdk5. ROS inhibition using Mito-Tempo almost completely inhibited cell 
Fig. 8 Inhibition of $\mathrm{mPTP}$ prevents breast cancer cell death caused by the loss of Cdk5. MDA MB-231 and MCF-7 breast cancer cells depleted of Cdk5 were treated with CsA (1 $\mu \mathrm{M})$, SFA $(2 \mu \mathrm{M})$, Mito-Tempo $(5 \mu \mathrm{M})$, or Mdivi-1 $(10 \mu \mathrm{M}) 4 \mathrm{~h}$ post-transfection. Surviving fractions of Cdk5-depleted cells were normalized with surviving fractions of cells transfected with control siRNA. Data represent means \pm SD from four independent experiments
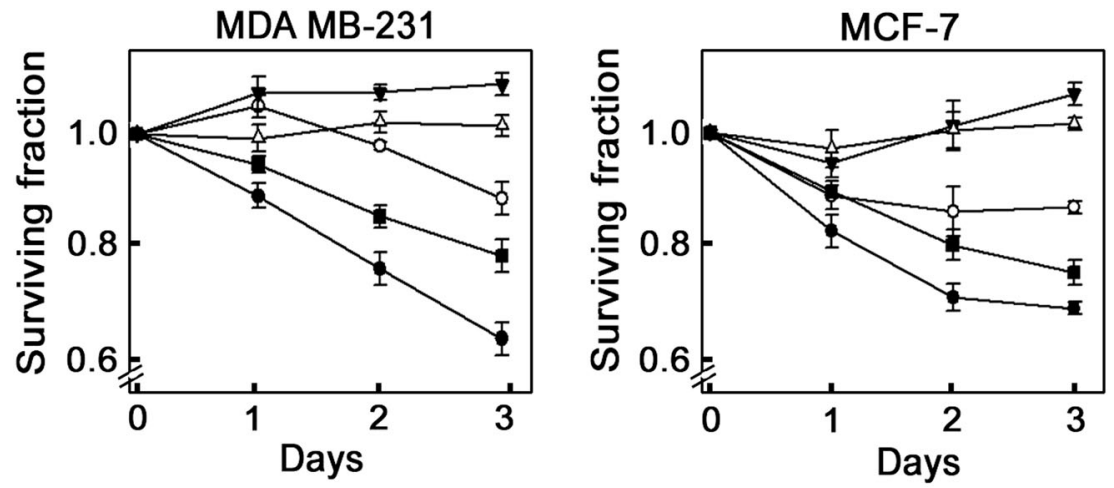

Cdk5 siRNA

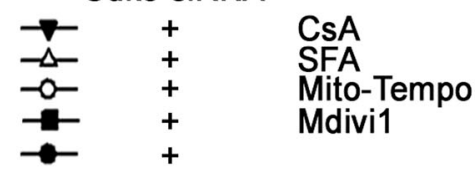

death with $90 \%$ survival of Cdk5-depleted cells. Conversely, inhibition of mitochondrial fission with Mdivi-1 had no inhibitory effect on the death of Cdk5-depleted cells. These findings further indicate that mitochondria-mediated apoptosis in cells depleted of Cdk5 occurs via an mPTPdependent mechanism and primarily through ROS increase.

\section{Discussion}

Cdk5 was previously shown to localize to the inner mitochondrial membrane [27]. The significance of Cdk5 in mitochondrial function, which controls the intrinsic apoptotic pathway, has been primarily investigated in neurons. However, the implicated roles of Cdk5 in cancer and apoptosis [10, 46], as well as its upregulated expression [3, 4, 47, 48], particularly in breast cancer cells [2], and its sensitizing effect on these cells to therapy when expression is lost [5-7], prompted our investigation on the potential function of Cdk5 in breast cancer cell mitochondria and mitochondria-mediated apoptosis in these cells. We identify mPTP as a target of Cdk5 and demonstrate that through mPTP, Cdk5 regulates mitochondrial depolarization and ROS level, as well as mitochondrial fragmentation, and consequently, the intrinsic apoptotic pathway in breast cancer cells. Our proposed mitochondria-mediated apoptotic pathway due to loss of $\mathrm{Cdk} 5$ in breast cancer cells is shown in Fig. 9.

Initially, we found that loss of Cdk5 in breast cancer cells causes mitochondrial depolarization, as observed upon Cdk5 inhibition by its pharmacological inhibitor, roscovitine, in HEK293T kidney epithelial cells. However, we additionally found that Cdk5 loss in breast cancer cells also increases mitochondrial ROS production and reduces cellular ATP level, indicating that Cdk5 loss leads to

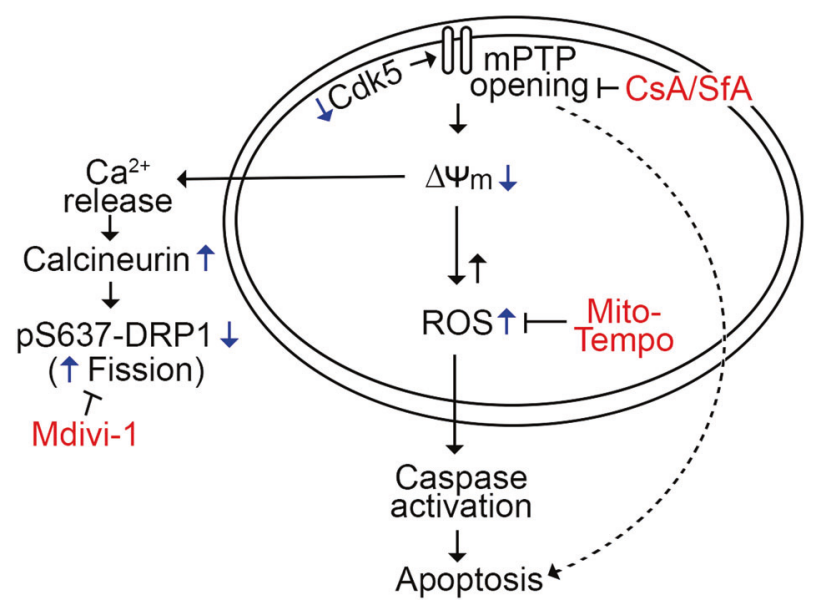

Fig. 9 Model for the intrinsic apoptotic pathway in breast cancer cells lacking Cdk5. Loss of Cdk5 in breast cancer cells causes opening of the MPTP, followed by mitochondrial depolarization and ROS increase, which leads to the activation of caspases and cell death. Opening of the MPTP and subsequent mitochondrial depolarization in cells lacking Cdk5 also results in calcium release and calcineurin activation that causes dephosphorylation of DRP1 at S637, which accompanies mitochondrial fragmentation in breast cancer cells lacking Cdk5

mitochondrial dysfunction. Mitochondrial depolarization due to reduced mitochondrial membrane potential, increased mitochondrial ROS, as well as decreased cellular ATP are likely due to an increase in permeability of the inner mitochondrial membrane that results from prolonged mPTP opening due to Cdk5 loss. This premise is consistent with our observation that treatment of Cdk5-deficient cells with an mPTP inhibitor, CsA or SfA, reverses the effects of Cdk5 loss on mitochondrial membrane potential and mitochondrial ROS level. CsA and SfA inhibit opening of the mPTP by binding to cyclophilin D and inhibiting its 
peptidyl-prolyl cis-trans isomerase activity $[49,50]$. Our findings indicate that mPTP opening due to Cdk5 loss lies upstream of mitochondrial depolarization and ROS increase in Cdk5-depleted cells. However, as specific inhibition of mitochondrial ROS with Mito-Tempo partially reverses mitochondrial depolarization, it appears that ROS increase contributes in part to mitochondrial depolarization in Cdk5depleted cells.

The fact that the high-conductance mPTP opening is activated by mitochondrial $\mathrm{Ca}^{2+}$ overload $[18,19]$ is further consistent with our observation that intracellular $\mathrm{Ca}^{2+}$ level is elevated in Cdk5-deficient cells. Thus, it is not surprising that the calcium-dependent calcineurin phosphatase activity is similarly upregulated in cells lacking Cdk5. Subsequently, the calcineurin target, DRP1, is dephosphorylated at $\mathrm{S} 637$ in these cells. These events that result from Cdk5 loss are associated with mitochondrial fragmentation. Indeed, calcineurin dephosphorylation of DRP1 at S637 stimulates DRP1 translocation to the mitochondria, leading to increased mitochondrial fission [32]. Conversely, DRP1 phosphorylation at S637 by PKA or $\mathrm{Ca}^{2+} /$ calmodulin-dependent protein kinase II promotes DRP1 detachment from the mitochondria causing inhibition of mitochondrial fragmentation [31, 32].

Previously, phosphorylation of DRP1 at S616 (human)/ S585 (rat) was found to have different effects [28]. For example, in pancreatic cancer cells [51] and during HeLa cell mitosis [52], DRP1 phosphorylation at S616 by Erk2 and Cdk1, respectively, causes mitochondrial fission. Conversely, Cdk5-dependent phosphorylation of DRP1 at S616 was linked to mitochondrial elongation during neuronal maturation [28]. In the current study, although Cdk5dependent DRP1 S616 phosphorylation in breast cancer cells may also contribute to mitochondrial elongation, loss of Cdk5-mediated DRP1 S616 phosphorylation (which corresponds to the lost phosphorylation in Cdk5-depleted cells: Supplementary Figure 8, lanes 2, 4 and 6) does not cause mitochondrial fragmentation. This is consistent with the report of Cereghetti et al. [32] that the phosphorylation status of Drp1 S637 is dominant over that of Drp1 S616. The fact that CsA and SfA treatments, which inhibit mitochondrial fragmentation in cells lacking Cdk5 (Figs. 7a, b and Supplementary Figure 7), has no effect on the phosphorylation status of DRP1 S616 in these cells (Supplementary Figure 8, lanes 2, 4, and 6) indicates that $\mathrm{mPTP}$ opening rather than lack of DRP1 S616 phosphorylation due to Cdk5 loss is the key element involved in mitochondrial fragmentation. As CsA was also suggested to act as a calcineurin inhibitor and inhibits Drp1 dephosphorylation in rat kidney proximal tubular cells subsequently inhibiting mitochondrial fission [53], the use of SfA in addition to CsA supports our view that mitochondrial fission due to Cdk5 loss is a result of MPTP dysregulation.
With increased mPTP opening, mitochondrial depolarization, and ROS increase in Cdk5-deficient cells, it is likely that IMS proteins, including cytochrome $\mathrm{C}$, are released from these cells. Thus, it is not surprising that we observed caspase- 3 and/or caspase- 9 activation in Cdk5-depleted MDA MB-231 and MCF-7 cells and subsequent apoptosis of these cells. Indeed, prolonged MPTP opening, which seems to result from Cdk5 loss in breast cancer cells, is required for the intrinsic apoptotic pathway [54, 55]. Absence of caspase-3 in MCF-7 cells [42] suggests that a caspase-3-independent mechanism is involved in the apoptosis of these cells upon Cdk5 depletion. Nonetheless, our findings point to $\mathrm{MPTP}$ opening and increased ROS, which is known to directly induce DNA damage [56, 57], as a mechanistic pathway that induces apoptosis upon loss of Cdk5. This view is consistent with the observed spontaneous DNA breaks and cell cycle arrest following Cdk5 depletion in breast and ovarian cancer cells $[5,6]$.

The ability of CsA and SfA to reverse DRP1 S637 dephosphorylation and completely inhibit mitochondrial fragmentation indicate that $\mathrm{MPTP}$ inhibition promotes DRP1 S637 phosphorylation and such phosphorylation prevents mitochondrial fragmentation in Cdk5-depleted cells. Our observation further supports our notion that mPTP opening and subsequent mitochondrial depolarization lie upstream of DRP1 S637 dephosphorylation and subsequent mitochondrial fragmentation. Given that CsA and SfA completely rescues cell death due to Cdk5 loss, and Mito-Tempo almost fully prevents such death while Mdivi1 has no inhibitory effect on death induced by Cdk5 loss indicate that intrinsic apoptosis in Cdk5-depleted cells occurs through an mPTP-dependent mechanism and predominantly via ROS increase. The specific molecular mechanism by which Cdk5 regulates $\mathrm{mPTP}$ opening is currently under investigation.

Together, our studies point to the existence of a novel Cdk5-regulated mPTP apparatus that is required for the functional maintenance of the mitochondria and for controlling the intrinsic apoptotic pathway in breast cancer cells. We propose that Cdk5 loss in breast cancer cells increases their sensitivity to drug therapy due to dysregulation of mPTP-dependent mitochondrial functions and exaggeration of therapy effects, including overwhelming DNA damage and intrinsic apoptosis through increased ROS production and caspase activation.

\section{Materials and methods}

\section{Materials}

MCF-7 and MDA MB-231 were from ATCC and HeLa mitoDSRed 2 cells were from Dr. BC Lee (University of 
Calgary). Dulbecco's modified Eagle's medium (DMEM), heat-inactivated fetal bovine serum (FBS), EDTA-Trypsin, antibiotic-antimycotic, $\mathrm{H}_{2}$-DCFDA, MitoSOX red, JC-1, MitoTracker green, and Fluo-4 AM were from Life Technologies Inc. Cdk5 (C-8), $\beta$-actin (C-19) and pro-caspase-9 (H-83) antibodies, and CsA and Mito-tempo were from Santa Cruz Biotech. Cleaved caspase-3 (5A1E), p-DRP S637 and DRP1 (4E11B11) antibodies were from Cell Signaling. Cdk5 and control siRNAs were synthesized at the University of Calgary Core DNA Services. The protease inhibitor cocktail and Mdivi-1 were from Sigma. SFA was obtained from Novartis (Switzerland).

\section{Cell culture}

Cells were cultured in DMEM supplemented with 10\% FBS and $100 \mathrm{U} / \mathrm{ml}$ each of penicillin and streptomycin, and maintained under $5 \% \mathrm{CO}_{2}$ at $37^{\circ} \mathrm{C}$.

\section{siRNA transfection}

Cells $\left(2.5 \times 10^{5}\right)$ were seeded on $6 \mathrm{~cm}$ dishes and transfected with $100 \mathrm{nM}$ Cdk5 (5'-GGGCUGGGAUUCUGUCAUA-3) or control (5'CGUACGCGGAAUACUUCGAUU-3') siRNA using Silentfect (Bio-Rad) for up to $72 \mathrm{~h}$.

\section{Protein quantitation}

Protein was quantified by Bradford assay (Bio-Rad).

\section{Western blotting}

Cell lysates $(30-50 \mu \mathrm{g})$ in RIPA buffer $(50 \mathrm{mM}$ Tris-HCl, pH 7.4, $150 \mathrm{mM} \mathrm{NaCl}, 1 \mathrm{mM}$ PMSF, $1 \mathrm{mM}$ EDTA, $1 \%$ Triton $\mathrm{X}-100,1 \%$ sodium deoxycholate, $0.1 \%$ sodium dodecyl sulfate (SDS)) containing a protease inhibitor cocktail were resolved in $12.5 \%$ SDS polyacrylamide gels and electroblotted onto nitrocellulose membranes. Membranes were blocked in 5\% skimmed milk then incubated with the indicated primary antibody (1:1000 dilution) at $4^{\circ}$ $\mathrm{C}$ overnight. After washing with tris-buffered saline (TBS) + Tween-20 (TBST) (50 mM Tris-HCl, pH 7.6, 0.1\% Tween-20, $0.8 \% \mathrm{NaCl}$ ), membranes were incubated with horseradish peroxidase-conjugated secondary antibody (1:10,000 dilution) for $1 \mathrm{~h}$. Immunoreactive bands were detected using ECL reagent (Amersham).

\section{Analysis for mitochondrial depolarization}

JC-1 and TMRM probes were used. JC-1 is a ratiometric dye that forms aggregates in highly polarized/energized mitochondria and emits an orange-red fluorescence at 595 $\mathrm{nm}$ (red/phycoerythrin). In depolarized mitochondria, JC-1 remains as monomers and emits green fluorescence at 530 $\mathrm{nm}$ (green/fluorescein isothiocyanate). Flow cytometry detects emission at both wavelengths and, based on the ratios in green vs red fluorescence in the two-parameter space, separates populations of cells with polarized mitochondria from those with depolarized mitochondria. TMRM, on the other hand, is a monochromatic probe or single wavelength dye that is readily sequestered by polarized/energized mitochondria. After $72 \mathrm{~h}$ of siRNA transfection, cells were stained with JC-1 dye $(5 \mu \mathrm{M})$ or TMRM $(5 \mu \mathrm{M})$ for $30 \mathrm{~min}$ at $37^{\circ} \mathrm{C}$ and analyzed by flow cytometry and fluorescence live cell microscopy using an Olympus $1 \times 71$ microscope, respectively.

\section{Flow cytometry}

Cells $\left(2.5 \times 10^{5}\right)$ seeded on $3.5 \mathrm{~cm}$ dishes and transfected with control or Cdk5 siRNA for $72 \mathrm{~h}$ were washed with Hank's balanced salt solution (HBSS) and harvested using Trypsin-EDTA. Cytoplasmic hydrogen peroxide and mitochondrial superoxide levels and mitochondrial membrane potential were measured by staining with $\mathrm{H}_{2}$-DCFDA (5 $\mu \mathrm{M})$, MitoSOX red $(5 \mu \mathrm{M})$, and JC-1 $(5 \mu \mathrm{M})$, respectively, in HBSS for $30 \mathrm{~min}$ at $37^{\circ} \mathrm{C}$ under $5 \% \mathrm{CO}_{2}$. Cells were then washed with HBSS, resuspended in ice-cold phosphate-buffered saline (PBS) and analyzed by flow cytometry using a fluorescein isothiocyanate filter $(530 \mathrm{~nm})$ for DCFDA, a phycoerythrin filter $(575 \mathrm{~nm})$ for MitoSOX red and both fluorescein isothiocyanate and phycoerythrin filters for JC-1 detection. Cells treated with $0.3 \% \mathrm{H}_{2} \mathrm{O}_{2}$ or 500 $\mu \mathrm{M}$ doxorubicin were used as positive controls for the detection of cytoplasmic hydrogen peroxide and mitochondrial superoxide, respectively.

\section{Live cell imaging}

Cells seeded on four-chamber cover glass (Lab-Tek) were stained with DCFDA $(5 \mu \mathrm{M})$, MitoTracker green $(200 \mathrm{nM})$ + MitoSOX red $(5 \mu \mathrm{M})$, or TMRM $(5 \mu \mathrm{M})$ to measure cytoplasmic hydrogen peroxide and mitochondrial superoxide levels and mitochondrial membrane potential, respectively. Images were taken under an Olympus $1 \times 71$ fluorescence microscope at $\times 100$ or $\times 160$ magnification.

\section{Confocal microscopy}

To examine mitochondrial morphology, Hela mitoDS cells seeded on coverslips were fixed in $4 \%$ paraformaldehyde and mounted on slides using ProLong Diamond Antifade Mountant with DAPI (Life Technologies Inc.). Cells were analyzed under a ZEN lite confocal microscope (Carl Zeiss). Mitochondrial images were taken from 10 different 
fields in each of three independent experiments. At least 50 cells were counted per coverslip.

\section{Immunofluorescence}

Breast cancer cells fixed and permeabilized with $0.2 \%$ Triton X-100 were incubated with TOM20 (1:1000 dilution, Santa Cruz, FL-145) antibody and subsequently goat antirabbit secondary antibody conjugated with Alexa fluor 488 . Breast cancer cells were analyzed under a super resolution confocal microscope (Leica) and ZEN lite confocal microscope (Carl Zeiss), respectively. Images were taken from 10 different fields in each of three independent experiments. At least 50 cells were counted per coverslip.

\section{ATP measurement}

Total cellular ATP level was measured using a bioluminescense assay (Life Technologies Inc.). Cell lysates were added to a reaction buffer containing $25 \mathrm{mM}$ Tricine $(\mathrm{pH}$ 7.8), $0.5 \mathrm{mM}$ D-luciferin, $1.25 \mu \mathrm{g} / \mathrm{ml}$ firefly luciferase, $5 \mathrm{mM}$ $\mathrm{MgSO}_{4}, 100 \mu \mathrm{M}$ EDTA, and $1 \mathrm{mM}$ DTT then incubated in the dark for $15 \mathrm{~min}$ at room temperature. Luminescence was measured using a luminometer at $560 \mathrm{~nm}$. A standard curve was generated and used to calculate ATP concentration.

\section{Calcium measurement}

Cdk5-depleted cells $\left(1 \times 10^{4}\right)$ were seeded on black bottom 96-well plates and stained with Fluo-4 acetoxymethyl ester (Fluo-4 AM; $5 \mu \mathrm{M}$ ) in HBSS (with $1.26 \mathrm{mM}$ calcium) for $30 \mathrm{~min}$ at $37^{\circ} \mathrm{C}$. Cells were washed twice with HBSS (without calcium) and analyzed using a fluorescence microplate reader at $494 / 506 \mathrm{~nm}$.

\section{Calcineurin activity}

Calcineurin activity was measured using an in vitro calciuneurin phosphatase activity assay kit (Abcam).

\section{Treatment with inhibitors of mitochondrial mPTP, ROS, and fragmentation}

Cdk5-depleted MDA MB-231, MCF-7 cells, or HeLa mitoDSRed 2 cells were treated for $24 \mathrm{~h}$ with CsA $(1 \mu \mathrm{M})$ or SFA $(2 \mu \mathrm{M})$ to inhibit mPTP, Mito-Tempo $(5 \mu \mathrm{M})$ to inhibit ROS, or Mdivi-1 $(10 \mu \mathrm{M})$ to inhibit mitochondrial fission.

\section{Survival assay}

CCK-8 reagent (Dojindo) was used to evaluate cell viability following siRNA transfection and treatment with mitochondrial inhibitors. Surviving Cdk5-depleted cells were calculated by normalizing the values with surviving control siRNA-transfected cells.

\section{Annexin V/7-AAD staining}

Cells washed with ice-cold PBS and resuspended in binding buffer (10 mM HEPES, $140 \mathrm{mM} \mathrm{NaCl}, 10 \mathrm{mM} \mathrm{CaCl}_{2}$ ) were incubated with annexin V-fluorescein isothiocyanate (Biotinium) and 7-AAD (3 $\mu \mathrm{g} / \mathrm{ml})$ for $15 \mathrm{~min}$ then subjected to flow cytometry (LSR II, BD Bioscience).

\section{Statistical analysis}

Student's $t$-test (unpaired, two-sided) or one or two-way analysis of variance (ANOVA) was used. Significance was set at $p<0.05$.

Acknowledgements We thank Novartis Pharma AG and Dr. BC Lee for providing SfA and HeLa mitoDSRed2 cells, respectively. We also thank Drs. Timothy Shutt, Karl Riabowol, Susan Lees-Miller, and Derek McKay for their critical reviews of the manuscript. This work was supported in part by grants from the CIHR (MOP-123400) and NSERC (RGPIN/312985-2011) to K-YL and an Alberta Cancer Foundation graduate studentship to SN.

\section{Compliance with ethical standards}

Conflict of interest The authors declare that they have no competing interests.

Open Access This article is licensed under a Creative Commons Attribution-NonCommercial-NoDerivatives 4.0 International License, which permits any non-commercial use, sharing, distribution and reproduction in any medium or format, as long as you give appropriate credit to the original author(s) and the source, and provide a link to the Creative Commons license. You do not have permission under this license to share adapted material derived from this article or parts of it. The images or other third party material in this article are included in the article's Creative Commons license, unless indicated otherwise in a credit line to the material. If material is not included in the article's Creative Commons license and your intended use is not permitted by statutory regulation or exceeds the permitted use, you will need to obtain permission directly from the copyright holder. To view a copy of this license, visit http://creativecommons.org/licenses/by-nc-nd/4.0/.

\section{References}

1. Rosales JL, Lee KY. Extraneuronal roles of cyclin-dependent kinase 5. Bioessay: News Rev Mol, Cell Dev Biol. 2006;28:1023-34.

2. Liang Q, Li L, Zhang J, Lei Y, Wang L, Liu DX, et al. CDK5 is essential for TGF-beta1-induced epithelial-mesenchymal transition and breast cancer progression. Sci Rep. 2013;3:2932.

3. Levacque Z, Rosales JL, Lee KY. Level of cdk5 expression predicts the survival of relapsed multiple myeloma patients. Cell Cycle. 2012;11:4093-5.

4. Liu JL, Wang XY, Huang BX, Zhu F, Zhang RG, Wu G. Expression of CDK5/p35 in resected patients with non-small cell lung cancer: relation to prognosis. Med Oncol. 2011;28:673-8. 
5. Turner NC, Lord CJ, Iorns E, Brough R, Swift S, Elliott R, et al. A synthetic lethal siRNA screen identifying genes mediating sensitivity to a PARP inhibitor. EMBO J. 2008;27:1368-77.

6. Zhang S, Lu Z, Mao W, Ahmed AA, Yang H, Zhou J, et al. CDK5 regulates paclitaxel sensitivity in ovarian cancer cells by modulating AKT activation, p21Cip1- and p27Kip1-mediated G1 cell cycle arrest and apoptosis. PLoS ONE. 2015;10:e0131833.

7. Zhu YX, Tiedemann R, Shi CX, Yin H, Schmidt JE, Bruins LA, et al. RNAi screen of the druggable genome identifies modulators of proteasome inhibitor sensitivity in myeloma including CDK5. Blood. 2011;117:3847-57.

8. Meuer K, Suppanz IE, Lingor P, Planchamp V, Goricke B, Fichtner L, et al. Cyclin-dependent kinase 5 is an upstream regulator of mitochondrial fission during neuronal apoptosis. Cell death Differ. 2007;14:651-61.

9. Weishaupt JH, Kussmaul L, Grotsch P, Heckel A, Rohde G, Romig $\mathrm{H}$, et al. Inhibition of CDK5 is protective in necrotic and apoptotic paradigms of neuronal cell death and prevents mitochondrial dysfunction. Mol Cell Neurosci. 2003;24:489-502.

10. Goodyear S, Sharma MC. Roscovitine regulates invasive breast cancer cell (MDA-MB231) proliferation and survival through cell cycle regulatory protein cdk5. Exp Mol Pathol. 2007;82:25-32.

11. Strock CJ, Park JI, Nakakura EK, Bova GS, Isaacs JT, Ball DW, et al. Cyclin-dependent kinase 5 activity controls cell motility and metastatic potential of prostate cancer cells. Cancer Res. 2006;66:7509-15.

12. Feldmann G, Mishra A, Hong SM, Bisht S, Strock CJ, Ball DW, et al. Inhibiting the cyclin-dependent kinase CDK5 blocks pancreatic cancer formation and progression through the suppression of Ras-Ral signaling. Cancer Res. 2010;70:4460-9.

13. Igney FH, Krammer PH. Death and anti-death: tumour resistance to apoptosis. Nat Rev Cancer. 2002;2:277-88.

14. Morciano G, Giorgi C, Bonora M, Punzetti S, Pavasini R, Wieckowski MR, et al. Molecular identity of the mitochondrial permeability transition pore and its role in ischemia-reperfusion injury. J Mol Cell Cardiol. 2015;78:142-53.

15. Bernardi P, Di Lisa F. The mitochondrial permeability transition pore: molecular nature and role as a target in cardioprotection. $\mathrm{J}$ Mol Cell Cardiol. 2015;78:100-6.

16. Halestrap AP. The $\mathrm{C}$ ring of the F1Fo ATP synthase forms the mitochondrial permeability transition pore: a critical appraisal. Front Oncol. 2014;4:234.

17. Bernardi P, Rasola A, Forte M, Lippe G. The mitochondrial permeability transition pore: channel formation by F-ATP synthase, integration in signal transduction, and role in pathophysiology. Physiol Rev. 2015;95:1111-55.

18. Lemasters JJ, Theruvath TP, Zhong Z, Nieminen AL. Mitochondrial calcium and the permeability transition in cell death. Biochim Biophys Acta. 2009;1787:1395-401.

19. Mnatsakanyan N, Beutner G, Porter GA, Alavian KN, Jonas EA. Physiological roles of the mitochondrial permeability transition pore. J Bioenerg Biomembr. 2017;49:13-25.

20. Batandier C, Leverve X, Fontaine E. Opening of the mitochondrial permeability transition pore induces reactive oxygen species production at the level of the respiratory chain complex I. J Biol Chem. 2004;279:17197-204.

21. Lemasters JJ, Nieminen AL, Qian T, Trost LC, Elmore SP, Nishimura $Y$, et al. The mitochondrial permeability transition in cell death: a common mechanism in necrosis, apoptosis and autophagy. Biochim Biophys Acta. 1998;1366:177-96.

22. Kinnally KW, Peixoto PM, Ryu SY, Dejean LM. Is mPTP the gatekeeper for necrosis, apoptosis, or both? Biochim Biophys Acta. 2011;1813:616-22.

23. Lemasters JJ, Qian T, He L, Kim JS, Elmore SP, Cascio WE, et al. Role of mitochondrial inner membrane permeabilization in necrotic cell death, apoptosis, and autophagy. Antioxid Redox Signal. 2002;4:769-81.

24. Verhagen AM, Ekert PG, Pakusch M, Silke J, Connolly LM, Reid GE, et al. Identification of DIABLO, a mammalian protein that promotes apoptosis by binding to and antagonizing IAP proteins. Cell. 2000;102:43-53.

25. Du C, Fang M, Li Y, Li L, Wang X. Smac, a mitochondrial protein that promotes cytochrome c-dependent caspase activation by eliminating IAP inhibition. Cell. 2000;102:33-42.

26. Suzuki Y, Imai Y, Nakayama H, Takahashi K, Takio K, Takahashi R. A serine protease, HtrA2, is released from the mitochondria and interacts with XIAP, inducing cell death. Mol Cell. 2001;8:613-21.

27. Fitzgerald JC, Camprubi MD, Dunn L, Wu HC, Ip NY, Kruger R, et al. Phosphorylation of HtrA2 by cyclin-dependent kinase- 5 is important for mitochondrial function. Cell Death Differ. 2012;19:257-66.

28. Cho B, Cho HM, Kim HJ, Jeong J, Park SK, Hwang EM, et al. CDK5-dependent inhibitory phosphorylation of Drp1 during neuronal maturation. Exp Mol Med. 2014;46:e105.

29. Jahani-Asl A, Huang E, Irrcher I, Rashidian J, Ishihara N, Lagace DC, et al. CDK5 phosphorylates DRP1 and drives mitochondrial defects in NMDA-induced neuronal death. Human Mol Genet. 2015;24:4573-83.

30. Xie Q, Wu Q, Horbinski CM, Flavahan WA, Yang K, Zhou W, et al. Mitochondrial control by DRP1 in brain tumor initiating cells. Nat Neurosci. 2015;18:501-10.

31. Cribbs JT, Strack S. Reversible phosphorylation of Drp1 by cyclic AMP-dependent protein kinase and calcineurin regulates mitochondrial fission and cell death. EMBO Rep. 2007;8:939-44.

32. Cereghetti GM, Stangherlin A, Martins de Brito O, Chang CR, Blackstone C, Bernardi P, et al. Dephosphorylation by calcineurin regulates translocation of Drp1 to mitochondria. Proc Natl Acad Sci USA. 2008;105:15803-8.

33. Bolin C, Boudra MT, Fernet M, Vaslin L, Pennaneach V, Zaremba $\mathrm{T}$, et al. The impact of cyclin-dependent kinase 5 depletion on poly(ADP-ribose) polymerase activity and responses to radiation. Cell Mol Life Sci. 2012;69:951-62.

34. Sun KH, de Pablo Y, Vincent F, Shah K. Deregulated Cdk5 promotes oxidative stress and mitochondrial dysfunction. J Neurochem. 2008;107:265-78.

35. Qu D, Rashidian J, Mount MP, Aleyasin H, Parsanejad M, Lira A, et al. Role of Cdk5-mediated phosphorylation of Prx2 in MPTP toxicity and Parkinson's disease. Neuron. 2007;55:37-52.

36. Wang Y, Nartiss Y, Steipe B, McQuibban GA, Kim PK. ROSinduced mitochondrial depolarization initiates PARK2/PARKINdependent mitochondrial degradation by autophagy. Autophagy. 2012;8:1462-76.

37. Kalogeris T, Bao Y, Korthuis RJ. Mitochondrial reactive oxygen species: a double edged sword in ischemia/reperfusion vs preconditioning. Redox Biol. 2014;2:702-14.

38. Rosdah AA, K Holien J, Delbridge LM, Dusting GJ, Lim SY. Mitochondrial fission-a drug target for cytoprotection or cytodestruction? Pharmacol Res Perspect. 2016;4:e00235.

39. Westermann B. Mitochondrial fusion and fission in cell life and death. Nat Rev Mol Cell Biol. 2010;11:872-84.

40. Elwi AN, Lee B, Meijndert HC, Braun JE, Kim SW. Mitochondrial chaperone DnaJA3 induces Drp1-dependent mitochondrial fragmentation. Int J Biochem Cell Biol. 2012;44:1366-76.

41. Wang S, Xiao W, Shan S, Jiang C, Chen M, Zhang Y, et al. Multipatterned dynamics of mitochondrial fission and fusion in a living cell. PLoS ONE. 2012;7:e19879.

42. Turner C, Devitt A, Parker K, MacFarlane M, Giuliano M, Cohen GM, et al. Macrophage-mediated clearance of cells undergoing caspase-3-independent death. Cell Death Differ. 2003;10:302-12. 
43. Wu S, Zhou F, Zhang Z, Xing D. Mitochondrial oxidative stress causes mitochondrial fragmentation via differential modulation of mitochondrial fission-fusion proteins. FEBS J. 2011;278:941-54.

44. Iqbal S, Hood DA. Oxidative stress-induced mitochondrial fragmentation and movement in skeletal muscle myoblasts. Am J Physiol Cell Physiol. 2014;306:C1176-1183.

45. Halestrap AP. What is the mitochondrial permeability transition pore? J Mol Cell Cardiol. 2009;46:821-31.

46. Wesierska-Gadek J, Gueorguieva M, Horky M. Roscovitineinduced up-regulation of p53AIP1 protein precedes the onset of apoptosis in human MCF-7 breast cancer cells. Mol Cancer Ther. 2005;4:113-24.

47. Leshchenko VV, Kuo PY, Shaknovich R, Yang DT, Gellen T, Petrich A, et al. Genomewide DNA methylation analysis reveals novel targets for drug development in mantle cell lymphoma. Blood. 2010;116:1025-34.

48. Abdullah C, Wang X, Becker D. Expression analysis and molecular targeting of cyclin-dependent kinases in advanced melanoma. Cell Cycle. 2011;10:977-88.

49. Fischer G, Wittmann-Liebold B, Lang K, Kiefhaber T, Schmid FX. Cyclophilin and peptidyl-prolyl cis-trans isomerase are probably identical proteins. Nature. 1989;337:476-8.

50. Clarke SJ, McStay GP, Halestrap AP. Sanglifehrin A acts as a potent inhibitor of the mitochondrial permeability transition and reperfusion injury of the heart by binding to cyclophilin-D at a different site from cyclosporin A. J Biol Chem. 2002;277:34793-9.

51. Kashatus JA, Nascimento A, Myers LJ, Sher A, Byrne FL, Hoehn KL, et al. Erk2 phosphorylation of Drp1 promotes mitochondrial fission and MAPK-driven tumor growth. Mol Cell. 2015;57:537-51.

52. Taguchi N, Ishihara N, Jofuku A, Oka T, Mihara K. Mitotic phosphorylation of dynamin-related GTPase Drp1 participates in mitochondrial fission. J Biol Chem. 2007;282:11521-9.

53. Cho SG, Du Q, Huang S, Dong Z. Drp1 dephosphorylation in ATP depletion-induced mitochondrial injury and tubular cell apoptosis. Am J Physiol Ren Physiol. 2010;299:F199-206.

54. Hirsch T, Marzo I, Kroemer G. Role of the mitochondrial permeability transition pore in apoptosis. Biosci Rep. 1997;17:67-76.

55. Precht TA, Phelps RA, Linseman DA, Butts BD, Le SS, Laessig TA, et al. The permeability transition pore triggers Bax translocation to mitochondria during neuronal apoptosis. Cell Death Differ. 2005;12:255-65.

56. Cooke MS, Evans MD, Dizdaroglu M, Lunec J. Oxidative DNA damage: mechanisms, mutation, and disease. FASEB J. 2003; 17:1195-214.

57. Jena NR. DNA damage by reactive species: mechanisms, mutation and repair. J Biosci. 2012;37:503-17. 